\title{
PREPRINT
}

Author-formatted, not peer-reviewed document posted on 24/11/2021

DOI: https://doi.org/10.3897/arphapreprints.e78423

Potential distribution of invasive boxwood blight pathogen (Calonectria pseudonaviculata) as predicted by process-based and correlative models

iD Brittany Barker, Leonard Coop, Chuanxue Hong 
Running Head: Potential distribution of invasive boxwood blight

\section{Potential distribution of invasive boxwood blight pathogen (Calonectria pseudonaviculata) as predicted by process-based and correlative models}

Brittany S. Barker ${ }^{1,2^{*}}$, Leonard Coop ${ }^{1,2}$, Chuanxue Hong ${ }^{3}$

${ }^{1}$ Oregon Integrated Pest Management Center, 4575 Research Way, Oregon State University, Corvallis, OR 97331 USA

${ }^{2}$ Department of Horticulture, Oregon State University, 4017 Agriculture and Life Sciences Building, Oregon State University, Corvallis, OR 97331 USA

${ }^{3}$ Hampton Roads Agricultural Research and Extension Center, Virginia Polytechnic Institute and State University, 1444 Diamond Springs Road, Virginia Beach, VA 23455 USA

*Corresponding author: Brittany Barker

E-mail: brittany.barker@oregonstate.edu

Key words: Buxus; plant disease; invasion; climatic suitability; CLIMEX; ensemble

Open Research Statement: The data, metadata, code, and derived products to reproduce the analysis and figures are currently available for reviewer access at GitHub repository (https://github.com/bbarker505/Cps-climSuit-modeling). Please note that site information for seven records from Oregon used for modeling are not provided due to confidentiality concerns. The final version of this repository will be archived at Zenodo.org or protocols.io prior to publication of this manuscript. 


\begin{abstract}
Boxwood blight, caused by the ascomycete fungi Calonectria pseudonaviculata and $C$. henricotiae, is an emerging plant disease of boxwood (Buxus spp.) that has had devastating impacts on the health and productivity of boxwood in both the horticultural sector and native ecosystems. In this study, we predicted the potential distribution of $C$. pseudonaviculata at regional and global scales and explored how climatic factors shape its known range limits. Our workflow combined multiple modeling algorithms to enhance the reliability and robustness of predictions. We produced a process-based climatic suitability model in the CLIMEX program and combined outputs of six different correlative modeling algorithms to generate an ensemble correlative model. All models were fit and validated using an occurrence record dataset $(\mathrm{N}=292$ records from 24 countries) comprised of positive detections of $C$. pseudonaviculata from across its entire known invaded range. Evaluations of model performance provided validation of good model fit for all models. A consensus map of CLIMEX and ensemble correlative model predictions indicated that not-yet-invaded areas in eastern and southern Europe and in the southeastern, midwestern, and Pacific coast regions of North America are climatically suitable for establishment. Most regions of the world where Buxus and its congeners are native are also at risk of establishment, which suggests that $C$. pseudonaviculata should be able to significantly expand its range globally if susceptible hosts exist. Our findings provide the first insight into the global invasion threat of boxwood blight, and are valuable to stakeholders who need to know where to focus surveillance efforts for early detection and rapid response measures to prevent or slow the spread of the disease.
\end{abstract}




\section{Introduction}

Invasive plant pathogens are a global threat to the health, productivity, and diversity of plants in both agricultural and native ecosystems (Fisher et al. 2012, Lovett et al. 2016, Paini et al. 2016,

5 Thakur et al. 2019). Plant pathogens including viruses, bacteria, oomycetes and fungi have been dispersing at unprecedented levels owing to increasing global trade and human travel, often remaining undetected or unidentified until they have spread and created visible impacts on hosts and recipient ecosystems (Fisher et al. 2012, Ricciardi et al. 2017, Thakur et al. 2019). In forest ecosystems, anthropogenic introductions of fungal and fungal-like pathogens are the main cause of emerging infectious diseases in trees, such as the well-known examples of chestnut blight and Dutch elm disease in North America (Lovett et al. 2016, Thakur et al. 2019). Ascomycete plant pathogens that can infect multiple host species in cultivated (e.g., parks, gardens, orchards, or nurseries) and native ecosystems tend to be particularly invasive, and include some of the most destructive pests of forest trees in countries with high levels of live plant trade (Santini et al. 2013, Lovett et al. 2016, Nahrung and Carnegie 2020).

Boxwood blight, also known as box blight, is an emerging disease of species in the genus

17 Buxus, many of which are major evergreen shrub crops and iconic landscape plants (Batdorf

18 2005, Daughtrey 2019, Hong 2019b), as well as a keystone forest species (Kolganikhina 2014,

19 Matsiakh 2016, Mitchell et al. 2018, Şimşek et al. 2019). This disease is caused by two invasive

20 ascomycete fungi, Calonectria pseudonaviculata (Cps) (Lombard et al. 2010) and C. henricotiae

21 (Gehesquière et al. 2016). Both pathogen species can infect and blight boxwood foliage,

22 resulting in rapid plant death. Calonectria henricotiae is only known to occur in Europe, whereas

23 Cps has a wider distribution that presently spans 24 countries primarily in Europe, Asia, and

24 North America (Gehesquière et al. 2016, Daughtrey 2019, Castroagudín et al. 2020a, EPPO

25 2020). Cps typically disperses long distances through human-mediated transport of diseased

26 liners (young plants) and nursery stock (Gehesquière 2014, Daughtrey 2019), often going

27 undetected because plants can be asymptomatic until exposed to weather patterns favoring

28 infection and subsequent symptom development (Gehesquière et al. 2013, LeBlanc et al. 2018).

29 After the initial detection of Cps in the United Kingdom in 1994 (Henricot et al. 2000), the

30 pathogen was reported from New Zealand in 1998 (Crous et al. 2002) and had spread to at least

31 eight countries in continental Europe by 2013 (Palmer and Shishkoff 2014). Cps was first 
32 detected in western Asia in 2010, and has since become widespread throughout native Buxus

33 forests in the Black Sea region of Turkey and the Caucasus (Gorgiladze et al. 2011, Akili et al.

34 2012, Gasich et al. 2013) up to the Caspian Hyrcanian forests of northern Iran (Mirabolfathy

35 2013, Rezaee et al. 2013, Khazaeli et al. 2018). Initial reports of Cps in North America in 2011

36 and 2012 were from the east coast of the United States (Douglas 2012, Ivors et al. 2012) and in

37 Oregon (Anonymous 2012) and British Columbia (Elmhirst et al. 2013), but the pathogen has

38 now been documented in at least 30 U.S. states throughout the Southeast, Northeast, Midwest,

39 and Pacific coast (Castroagudín et al. 2020b, Hall et al. 2021).

Boxwood blight caused by $C p s$ poses a serious threat to the horticultural industry, local economies, and ecosystem integrity (LeBlanc et al. 2018, Mitchell et al. 2018, Daughtrey 2019).

42 In the United States, the ornamental horticulture industry has sustained significant financial

43 losses because boxwood is the number one evergreen shrub sold, with an annual wholesale value

44 greater than \$140 million (USDA National Agricultural Statistics Service 2020). Boxwood blight

45 increases the cost of producing boxwood because infected plants are unsellable and must be

46 destroyed, and controlling the disease with chemical treatments is expensive (LaMondia 2015,

47 Daughtrey 2019, Hall et al. 2021). Total economic losses resulting from boxwood blight in

48 Connecticut alone amounted to more than $\$ 3$ million within the first year of detection (LaMondia

49 2015). Additionally, the disease has caused declines in native Buxus forests in western Asia,

50 which has reduced habitat for Buxus-associated biodiversity and negatively impacted ecosystem

51 services (Mirabolfathy et al. 2013, Matsiakh 2016, Lehtijärvi et al. 2017, Mitchell et al. 2018).

52 The full host range of Cps is unknown; however, none of 11 tested Buxus species were immune

53 to boxwood blight (Henricot et al. 2008, Shishkoff et al. 2015, LaMondia and Shishkoff 2017),

54 and certain Buxaceae plants in the genera Sarcococca Lindl. (Henricot et al. 2008, Malapi-Wight

55 et al. 2016, Ryan et al. 2018) and Pachysandra Michx. (LaMondia et al. 2012, LaMondia and Li

56 2013, Kong et al. 2017) are also vulnerable to infection. Artificial inoculations demonstrated that

57 the host range may even include plants in other taxonomic families (Richardson et al. 2020).

58 These findings suggest that Cps could be a significant threat to at least some of the ca. 100 Buxus

59 species, which are primarily distributed in tropical and subtropical zones of the world, and

60 potentially to other Buxaceae and non-Buxaceae species. Despite the rapid and ongoing spread

61 of Cps, assessments of establishment risk for areas which have not (yet) been invaded are not

62 well developed. Identifying areas which are conducive for establishment by invasive plant 
63 pathogens can guide surveillance efforts and increase the likelihood that pathogens are detected

64 early, which is the most effective and cost-efficient method to avoid the potential ecological,

65 economic, and societal consequences of their spread (Santini et al. 2013, Lovett et al. 2016,

66 Hong 2019a).

67 In this study, we used multiple climatic suitability modeling approaches to predict the

68 potential distribution of $C p s$ at regional and global scales and explore how climatic factors shape

69 its known range limits. Climatic suitability models, also known as ecological niche models,

70 habitat suitability models, bioclimatic envelope models, or climatic envelope models (Elith and

71 Graham 2009), have become an important tool for assessing establishment risk for invasive plant

72 fungal pathogens because their growth and survival is closely related to climatic conditions,

73 particularly temperature and moisture (Magarey et al. 2007, Lantschner et al. 2019). Indeed, the

74 epidemiology of Cps is strongly influenced by longer periods of high relative air humidity

75 combined with warm temperatures (Gehesquière 2014, Avenot et al. 2017, LeBlanc et al. 2018).

76 We used a workflow that combined multiple modeling algorithms to reduce predictive

77 uncertainty of single-models, which should enhance the reliability and robustness of predictions

78 and provide independent perspectives into the potential distribution of invasive species (Capinha

79 and Anastácio 2011, Lantschner et al. 2019). First, we used the CLIMEX program (Sutherst and

80 Maywald 1985, Kriticos et al. 2016) to develop a climatic suitability model for Cps based on its

81 predicted response to growth- and survival-limiting temperature and moisture factors. The

82 CLIMEX approach is considered process-based because models are typically parameterized

83 using a combination of eco-physiological data (e.g., temperature thresholds for development and

84 survival) and point observations of occupancy or abundance from the species' known

85 geographical distribution (Sutherst and Maywald 1985, Kriticos et al. 2016). CLIMEX is one of

86 the most frequently used climatic suitability modeling tools for invasive pest species, including

87 for plant fungal pathogens (Ireland and Kriticos 2019, Lantschner et al. 2019).

88 Next, we developed climatic suitability models for Cps using multiple correlative

89 modeling algorithms and combined their predictions into an ensemble model to potentially

90 increase predictive performance (Marmion et al. 2009, Shabani et al. 2016, Hao et al. 2020).

91 Correlative climatic suitability models (hereafter correlative models) involve statistically linking

92 spatial climatic data to species location records to estimate the probability of other locations

93 being part of the species distribution (Elith and Graham 2009, Dormann et al. 2012). Correlative 
94 models are thought to be less reliable in predicting a species' potential distribution in novel

95 climates than process-based models, but their advantages include their lower input data needs

96 and generally lower number of parameters (Kearney and Porter 2009, Dormann et al. 2012,

97 Peterson et al. 2015). For example, correlative models only require known distribution data as an

98 input whereas CLIMEX models requires a more extensive baseline knowledge of the species. By

99 joining process-based and correlative approaches in a combined workflow, we strived to

100 incorporate advantages of each approach (Lantschner et al. 2019). Our specific objectives were

101 to identify range-limiting climatic factors for Cps using each modeling approach, and to compare

102 the models' predictions of climatic suitability and the overall potential distribution of the

103 pathogen at both regional and global scales. The models developed for this study may help with

104 identifying locations for surveillance to detect Cps before it establishes, and they may provide

105 insight into its potential native range, which is hypothesized to be in a host center of diversity for

106 Buxus in East Asia, the Caribbean, or Madagascar (LeBlanc et al. 2018, Daughtrey 2019).

108 Methods

109

110 Boxwood blight occurrence records

111 To fit and validate CLIMEX and correlative models, we compiled 292 occurrence records for

112 Cps from 24 countries, which spans the entire known distribution of the pathogen (Europe, Asia,

113 New Zealand, and North America; Appendix 1, Supporting information). Occurrence records

114 were derived from peer-reviewed literature, theses, reports, media sources (e.g., online news

115 articles), the Global Biodiversity Information Facility (2nd April 2021; GBIF Occurrence

116 Download https://doi.org/10.15468/dl.44z8yr), CERIS Pest Tracker

117 (https://pest.ceris.purdue.edu/), the Agricultural Research Service Fungal Database

118 (https://nt.ars-grin.gov/fungaldatabases/), and personal communications. We excluded any record

119 collected from garden centers and/or newly established plantings with boxwood plant stocks

120 originating from another state. Ideally, positive confirmations of Cps should be based on both

121 morphological and laboratory-collected data (e.g., genetic and physiological characterization)

122 because some symptoms of boxwood blight overlap somewhat with those of other boxwood

123 diseases (Daughtrey 2019). For several Cps records, confirmations were based only on

124 morphological data, or the source did not provide any information on the confirmation process. 
125 However, these records were within or close to areas where $C p s$ is known to occur, which 126 suggests the species was correctly identified. Most records for the United States (101/156= $12765 \%$ ) were spatially resolved only to the county level due to confidentiality concerns, whereas all 128 other records were resolved to at least the city level.

130 CLIMEX model

131 The CLIMEX model for Cps was generated using CLIMEX version 4.0 (Kriticos et al. 2016).

132 CLIMEX uses a re-formatted version of the CliMond dataset (Kriticos et al. 2012), which is 133 comprised of 35 Bioclim variables for the 1961-1990 time period (https://www.climond.org/).

134 CLIMEX data have a $10^{\prime}$ resolution ( $\mathrm{ca} .55 \mathrm{~km}^{2}$ at the equator) spatial resolution, which is 135 appropriate given that most records from the United States were spatially resolved only to county 136 level. Eco-physiological information for parameterizing a CLIMEX model for Cps was derived

137 from published studies on the impacts of temperature and moisture on the development and 138 survival of the vegetative growing stage as well as the more stress-tolerant microsclerotia stage, 139 which can remain dormant on soil surfaces for months or even years (Henricot et al. 2008, Dart 140 et al. 2015). We fine-tuned CLIMEX parameters by fitting the model to occurrence records from 141 Europe and western Asia $(\mathrm{N}=125)$, where the species may have had more time to fill its 142 climatic niche compared to more recently invaded regions. Only one parameter was adjusted at a 143 time during this process. We then validated the CLIMEX model by verifying that records from 144 North America $(\mathrm{N}=159)$ and New Zealand $(\mathrm{N}=8)$ fell within climatically suitable areas as 145 defined by the ecoclimatic index, which ranges from 0 to 100 and describes the overall suitability 146 of a location for long-term persistence by a species (Sutherst 2014, Kriticos et al. 2016). The 147 ecoclimatic index integrates the annual growth index, which describes the potential for 148 population growth (also ranging from 0 to 100), with annual stresses that limit survival during 149 unfavorable intervals (cold, heat, dry, and wet stress) and potentially other limiting factors such

150 as diapause. A species is considered to be excluded from locations which have an ecoclimatic 151 index of zero, whereas increasing ecoclimatic index values signify higher potential for growth 152 and survival (Kriticos et al. 2016). We report CLIMEX model parameters for Cps in Table 1 and 153 describe how we derived each parameter value in the next two subsections. 
156 Four temperature index parameters in CLIMEX describe the ability for temperature-driven 157 population growth: DV0 (limiting low temperature), DV1 (lower optimal temperature), DV2 158 (upper optimal temperature), and DV3 (limiting high temperature). Cps may develop at 159 temperatures as low as $5^{\circ} \mathrm{C}$ (Henricot and Culham 2002, Gehesquière 2014, Gehesquière et al. 160 2016), but we set DV0 to $9{ }^{\circ} \mathrm{C}$ to avoid potential biases resulting from canopy temperatures being 161 lower than estimates from weather stations, which can produce errors in plant disease models 162 (Pfender et al. 2012). We set DV1 and DV2 to 21 and $25^{\circ} \mathrm{C}$, respectively, because this 163 temperature range is associated with optimal growing conditions in both field and laboratory settings (Henricot and Culham 2002, Gehesquière 2014, Gehesquière et al. 2016, Avenot et al. 2017, Lehtijärvi et al. 2017). We used an upper threshold of $29^{\circ} \mathrm{C}$ because $C p s$ colonies exhibit a

166 low growth rate and have irregular and sclerotized morphologies at temperatures $\geq 28{ }^{\circ} \mathrm{C}$

167 (Gehesquière 2014, Gehesquière et al. 2016, Avenot et al. 2017). Our unpublished re-analysis of 168 Gehesquiere (2014) data indicated that 500 degree-hours during continuous leaf wetness would 169 cause between $c a$. 10-50\% infection for B. sempervirens and B. s. var 'Suffruticosa', which is 170 equivalent to 20 degree-days. However, CLIMEX has no way to integrate moisture with degree171 day calculations, so we used a 10× higher value of 200 as a rough stand-in for the degree-days 172 per generation parameter (PDD). The PDD value therefore has no true meaning with regard to 173 actual infection conditions because it accounts only for favorable temperatures.

174 CLIMEX describes the overall moisture characteristic of a location using estimates of 175 soil moisture, which combine the interactions of temperature, rainfall and evapotranspiration. 176 While precipitation and dew point are the primary moisture drivers of Cps growth (Shishkoff and 177 Camp 2016, Avenot et al. 2017, LeBlanc et al. 2018), the use of soil moisture in CLIMEX 178 should capture the species' response to its moisture environment in a broad sense. Four soil 179 moisture (SM) index parameters describe the influence of moisture on population growth: SM0 180 (limiting low moisture), SM1 (lower optimal moisture), SM2 (upper optimal moisture), and SM3 181 (limiting high moisture). For each SM parameter, a value of 0 indicates no soil moisture, a value 182 of 0.5 indicates soil moisture content is $50 \%$ of capacity, a value of 1 indicates that soil moisture 183 content is $100 \%$ of capacity, and a value $>1$ indicates a water content greater than the soil 184 holding capacity (Kriticos et al. 2016). We set SM0 to 0.2, which is higher than the permanent 185 wilting point of plants in CLIMEX $(\mathrm{SM} 0=0.1)$, because pathogens including Cps require free 186 water for parts of their lifecycles. We set SM1 to 0.7 because using higher values resulted in 
187 certain occurrence records from more inland areas of the Black Sea and Caspian Sea regions

188 being excluded (i.e., ecoclimatic index $=0$ ). The upper optimal value (SM2) was set to 1.7 to

189 ensure that wet conditions were suitable, and the upper threshold (SM3) was set to 3 to remove

190 any constraints on growth related to very high rainfall.

\section{Temperature and moisture stress parameters}

193 The cold and heat stress thresholds (TTCS and TTHS, respectively) in CLIMEX define the

194 temperature below (TTCS) or above (TTHS) which stress begins to accumulate according to a

195 weekly rate (Kriticos et al. 2016). For example, if the average weekly maximum temperature

$196\left(\mathrm{~T}_{\max }\right)$ exceeds TTHS, then heat stress $=\left(\mathrm{T}_{\max }-\mathrm{TTHS}\right) \times$ THHS, where THHS is described by

197 the slope of the relationship between weekly heat stress and average weekly $\mathrm{T}_{\max }$. The threshold

198 temperature function in CLIMEX has a multiplicative factor (referred to as "week number") that

199 causes stress to accumulate exponentially during consecutive weeks. To help identify appropriate

200 TTCS and THHS values, we extracted minimum temperature of the coldest week data (bio6) and

201 maximum temperature of the warmest week (bio6) data from the CliMond dataset for Cps

202 occurrence records from Europe and western Asia. According to this analysis, all localities in the

203 coldest parts of Cps's distribution, which occur in northern Europe and high-elevation parts of

204 Georgia, were in areas where weekly minimum temperatures were $\geq-8{ }^{\circ} \mathrm{C}$. This finding is

205 consistent with temperature limits of the most cold tolerant boxwood varieties, which are almost

206 impossible to grow in areas where temperatures drop below $-10^{\circ} \mathrm{C}$ (United States Department of

207 Agriculture 1976), and with laboratory studies of Cps microsclerotia survival (Shishkoff and

208 Camp 2016, Yang and Hong 2018). We set TTCS to $-10^{\circ} \mathrm{C}$ and adjusted the cold stress rate

209 (THCS) to ensure that the coldest localities for Cps in Europe and western Asia fell within areas

210 where the ecoclimatic index exceeded zero. Additionally, we considered maps of the northern

211 range limit for European boxwood B. sempervirens (Pojark.) in Norway, which is largely

212 confined to districts south of $62^{\circ} \mathrm{N}$ (Salvesen and Kanz 2009).

213 We set TTHS to $32{ }^{\circ} \mathrm{C}$ and adjusted the heat stress accumulation rate (HDS) so that

214 records from the hottest part of Cps's distribution, which occur in northern Iran along the

215 Caspian Sea (Mirabolfathy 2013, Khazaeli et al. 2015), had ecoclimatic index values exceeding

216 zero. Microsclerotia have been shown to survive at $40^{\circ} \mathrm{C}$ for at least 24 hours (Yang and Hong

217 2018); however, other data sources suggest that heat stress accumulates at lower temperatures. 
218 An upper lethal temperatures of $33^{\circ} \mathrm{C}$ has been suggested by Henricot and Culham (2002) based 219 on a laboratory study of conidial growth (Henricot and Culham 2002), and by Hagan and Conner 220 based on field reports. Additionally, microsclerotia died after two to five months at $30^{\circ} \mathrm{C}$ under 221 laboratory conditions (Shishkoff and Camp 2016), which, if translated to field conditions, would 222 be slightly cooler in the soil under a canopy than in weather shelters. All but a single locality 223 record for Cps in Europe and western Asia occurred in areas where weekly maximum

224 temperatures fell below $32{ }^{\circ} \mathrm{C}$, which provides further evidence that this temperature is an 225 appropriate heat stress threshold.

226 Whereas extremely low soil moisture reduces survival of Cps (Shishkoff and Camp 2016,

227 Avenot et al. 2017), excessive moisture is not known to be detrimental to survival of the 228 pathogen. We set the dry stress threshold (SMDS) to 0.2 and weekly dry stress rate (HDS) to $229-0.001$ because this contributed to the exclusion of the species (ecoclimatic index $=0$ ) from 230 relatively arid areas beyond the Black Sea and Caspian Sea regions, where boxwood does not 231 occur (Hūšang 1989, Lehtijärvi et al. 2017). Conversely, we used a relatively high wet stress 232 threshold (SMWS) of 3.0 and set the rate of wet stress accumulation (HWS) to 0.005 . We did not 233 apply the hot-dry (interaction) stress parameter in CLIMEX because preliminary analyses 234 indicated that it did not assist in modeling the potential distribution.

Irrigation

237 To explore how supplemental irrigation may influence climatic suitability and the potential 238 distribution of Cps, we ran the CLIMEX model both with and without an option to apply 'top239 up' amounts irrigation (rainfall) of $2.5 \mathrm{~mm} \mathrm{day}^{-1}$ during the summer (Kriticos et al. 2016).

240 Summer irrigation is regularly used in horticultural settings where boxwood is grown (United 241 States Department of Agriculture 1976), and it can play a key role in Cps growth and survival by 242 increasing the humidity to levels conducive for sporulation and infection (Gehesquière 2014, 243 Bartíková et al. 2020b). Henceforth the model which did not include irrigation is simply referred 244 to as the "CLIMEX model."

\section{Correlative models}

247 We generated correlative models for Cps in the ENMTML R package v. 1.0.0 (de Andrade et al. 248 2020) in $\mathrm{R}$ version 4.0.5 (R Development Core Team 2021). ENMTML provides a suite of 
249 functions to preprocess locality and environmental input data, fit models using a variety of

250 algorithms, evaluate model performance for each algorithm, and combine model outputs to 251 produce an ensemble model (de Andrade et al. 2020). We fit models using occurrence records 252 from Europe, western Asia, and North America because prediction accuracy of correlative 253 models is often higher when a larger proportion of the realized climatic niche is sampled 254 (Beaumont et al. 2009, Taylor and Kumar 2012, Pili et al. 2020).

255 Two filtering steps were taken on records to reduce biased geographic sampling, which 256 can strongly affect the predictive performance of correlative climatic suitability models that use 257 presence-only data (Veloz 2009, Kramer-Schadt et al. 2013). First, we reduced the effects of 258 clustered sampling by implementing the "pp.subsample" function in the spatialEco R package v. 1.3.7 (Evans 2021), which created a subsample of $80 \%$ of Cps records for both regions based on 260 the expected spatial intensity function of the observed data. Second, we thinned records within 261 ENMTML using the "CELLSIZE" method of the "thin_occ" function in the spThin R package v. 2620.2 .0 (Aiello-Lammens et al. 2015), which removes records that occur within a distance of two 263 cells. This process resulted in 67 records for Europe and western Asia $(67 / 163=41 \%)$, and 96 264 records for North America $(96 / 163=59 \%)$. Maps presenting the full and subsampled occurrence records for both regions are presented in Fig. S1 (Supporting information).

Twenty-seven bioclimatic variables from the CliMond dataset were used to generate correlative SDMs (Kriticos et al. 2012). The first 19 bioclimatic variables (bio1-bio19) are derived from the WorldClim data set and represent annual, weekly (interpolated from monthly), and seasonal trends and extremes in temperature and precipitation (Hijmans et al. 2005). Eight bioclimatic variables that describe weekly, quarterly and annual indices of soil moisture (bio28bio35) were also included because considering soil moisture should increase comparability of model predictions between CLIMEX and correlative models. We cropped bioclimatic layers to

274 used for model fitting can significantly improve model performance (Cooper and Soberón 2018). 275 This included areas between $25.5^{\circ} \mathrm{N}$ and $25.5^{\circ} \mathrm{S}$ in both regions, between $170{ }^{\circ} \mathrm{W}$ and $51^{\circ} \mathrm{W}$ in 276 North America (conterminous United States and southern Canada), and between $12^{\circ} \mathrm{W}$ and 61.9 $277{ }^{\circ} \mathrm{E}$ in Eurasia (western Europe to the eastern border of Iran).

278 A principal component analysis (PCA) was conducted based on the correlation matrix of 279 the 27 cropped climate variables to reduce variable collinearity, which can reduce uncertainty of 
280 correlative models and increase performance of models projections into new regions (Veloz 281 2009, Dormann et al. 2013, Petitpierre et al. 2017, De Marco and Nóbrega 2018). We produced a 282 dataset comprised of six principal components (PCs) that explained at least $95 \%$ of the total 283 variance (De Marco and Nóbrega 2018) using the "rasterPCA" function in the RSToolbox R 284 package v. 0.2.6 (Leutner and Horning 2017). The first and second PC axes explained the highest proportion of the total variance $(52.2 \%+27.3 \%=79.5 \%)$ and had strongest contributions from moisture and temperature variables, respectively (Table 2). The first PC axis (PC1) had a strong positive loading for soil moisture seasonality (bio31) and strong negative loadings for precipitation and soil moisture during warm seasons (bio18 and bio34, respectively), reflecting lower warm season moisture and higher moisture seasonality at positive PC1 scores (Table 2 and Fig. S2, Supporting information). The second PC axis (PC2) had strong positive loadings for temperatures during cold seasons (bio6 and bio11) and strong negative loadings for temperature

292 seasonality and annual range (bio4 and bio7, respectively), reflecting lower winter temperatures 293 and higher temperature seasonality at positive PC2 scores. PC axes 3 through 6 explained the 294 remaining $16.3 \%$ of total variance and were primarily related to temperatures during warm and 295 wet seasons (PC3), wet season precipitation (PC4), diurnal cold and wet season temperature range and soil moisture (PC5), and dry season precipitation and precipitation seasonality (PC6).

Six different algorithms were used to fit correlative models in ENMTML and assess variable importance. These included: boosted regression tree (Elith et al. 2008), generalized additive models (Guisan et al. 2002), Gaussian process usage (Golding and Purse 2016), Maxent 301 forests (Prasad et al. 2006), and support vector machine (Guo et al. 2005). ENMTML sources 302 modeling algorithm functions from multiple different $\mathrm{R}$ packages and uses default settings 303 (Table S1, Supporting information) unless the user manually edits the program. We applied 304 default settings for all algorithms except for Maxent, in which we increased the regularization 305 multiplier parameter from one (default) to four to avoid model overfitting (Phillips et al. 2006).

306 We used the three-step pseudo-absence selection method of Senay et al. (2013) to allocate 307 pseudo-absences, wherein a sample of environmentally dissimilar locations within a $400 \mathrm{~km}$ 308 buffer around occurrence records were identified and then sampled using k-means clustering. 309 Information on the individual R package repositories and settings used for each modeling 310 algorithm is presented in Table $\mathrm{S} 1$, Supporting information. 
In the post-processing stage of ENMTML, we evaluated model performance for each

312 algorithm and produced an ensemble model from single-model outputs. Model performance was

313 assessed using 50 bootstrapped replicates for each algorithm, with a random $70 \%$ subset of

314 records used to train the model and 30\% reserved for validation. Model replicates were then

315 projected at a global scale using the same climatic PC predictors. We evaluated SDMs using the

316 area under the receiving operating characteristic curve (AUC), true skill statistics (TSS), Kappa,

317 Jaccard, Sørensen, Boyce, and F-measure on presence-background data $\left(\mathrm{F}_{\mathrm{pb}}\right)$ metrics (Boyce et

318 al. 2002, Allouche et al. 2006, Li and Guo 2013, Leroy et al. 2018). Similarity indices from

319 community ecology (Jaccard, Sørensen and $\mathrm{F}_{\mathrm{pb}}$ ) may provide better estimations of model

320 discrimination capacity than metrics which depend on prevalence (the proportion of sites where

321 the species is present) including AUC and Kappa (Allouche et al. 2006, Li and Guo 2013, Leroy

322 et al. 2018).

323 An ensemble model was produced by calculating a weighted mean of suitability

324 predictions (probability of occurrence) of the best models across all algorithms, defined as those

325 which had an $\mathrm{F}_{\mathrm{pb}}$ metric exceeding the average for all models (Thuiller 2004). Additionally, we

326 overlaid predictions of presence-absence produced by the six algorithms to compare

327 delimitations of the potential distribution. The maximum TSS threshold, which maximizes the

328 sum of sensitivity (proportion of correctly predicted observations of species presence) and

329 specificity (proportion of correctly predicted observations of species absence), was used to

330 produce presence-absence predictions because it may have higher accuracy than other threshold

331 methods (Liu et al. 2005, França and Cabral 2019). We tested the climatic similarity between the

332 model calibration and global projection areas using a mobility-oriented parity (MOP) analysis

333 (Owens et al. 2013) to identify potential regions where strict extrapolation occurred, wherein

334 climatic conditions are outside of the range of conditions in the calibration area. Model

335 extrapolation into new regions or climate change scenarios may change the correlation structure

336 between parameters and thus lead to unreliable predictions when projected outside the

337 environmental space (Dormann et al. 2013, Owens et al. 2013, Petitpierre et al. 2017). The MOP

338 analysis sampled $10 \%$ of reference points from the environmental space of the calibration area

339 and was conducted within ENMTML using the "MOP" function in kuenm R package v. 1.1.7

340 (Cobos et al. 2019). Finally, we produced consensus maps depicting areas of overlap in the

341 potential distribution as estimated by presence-absence predictions of the ensemble correlative 
342 model and the CLIMEX model. In theory, an ecoclimatic index which exceeds 0 indicates a

343 potential for establishment (Kriticos et al. 2016); however, we defined the potential distribution

344 in CLIMEX as areas which had an ecoclimatic index of at least 10 because most occurrence

345 records $(286 / 292=98 \%)$ met this criterion.

347 Results

Model evaluation and variable importance in correlative models

350 Validation analyses indicated very good performance of the CLIMEX model and correlative 351 models. Of the 124 occurrence records from Europe and western Asia used for fine-tuning 352 CLIMEX parameters, only one fell within an unsuitable location (i.e., ecoclimatic index =0). All 353 occurrence records from North America and New Zealand were in areas that CLIMEX predicted 354 to be climatically suitable (average ecoclimatic index $=24$, range $=10$ to 60 ), which provided 355 validation of good model fit. Evaluation metrics for the final ensemble correlative model were 356 very high (Table 3): the AUC, TSS, Kappa, Jaccard, Sørensen, and Boyce metrics exceeded 0.99 357 (values $>0.90$ are considered excellent performance) and $\mathrm{F}_{\mathrm{pb}}$ was $1.99\left(\mathrm{~F}_{\mathrm{pb}}=2 \times\right.$ Jaccard). 358 Metric values for single models across 50 repetitions were also high, with an average of 0.998 359 for AUC (range = 0.996-1), 0.981 for Kappa (range $=0.974-0.992), 0.981$ for TSS $($ range $=$ 360 0.975-0.992), 0.981 for Jaccard (range = 0.975-0.992), 0.991 for Sørensen (range = $3610.987-0.996$ ), and 1.96 for $\mathrm{F}_{\mathrm{pb}}$ (range = 1.95-1.98). The PC2 variable contributed most strongly 362 (average $=47 \%$ ) to correlative models (Table 4), indicating an important role for cold 363 temperatures and temperature seasonality in shaping the distribution of Cps. The PC1 variable 364 provided the next highest contribution to correlative models (average $=24.3 \%$ ), indicating that 365 warm season moisture and moisture seasonality (PC1) are also important range-limiting factors.

366 On average, the remaining PC variables had relatively low contributions (PC3 $=8.5 \%$, PC4 $=$ $3674.8 \%$, PC5 $=9.8 \%$, PC6 $=5.6 \%)$.

Climatic suitability for and potential distribution of $\mathrm{Cps}$ in Europe and western Asia

370 CLIMEX and the ensemble correlative model predictions of climatic suitability and the potential 371 distribution for Cps in Europe and western Asia were mostly concordant (Fig. 1). CLIMEX 372 predicted the highest ecoclimatic and population growth index values in the Atlantic region of 
373

374

375

376

377

378

379

380

western Europe, coastal areas of southern Europe, and the Black and Caspian Sea regions of western Asia (Figs 1A and 2A, respectively), which is consistent with the ensemble correlative model's predictions of high climatic suitability for these areas (Fig. 1C). Consequently, these regions were included in the potential distribution according to both models (Fig. 1D). In general, the models predicted lower climatic suitability throughout most of central and eastern Europe, but these areas were nonetheless included in the potential distribution. CLIMEX's estimate of the potential distribution extended farther east than that of the ensemble correlative model to include all of the Baltic states and Belarus, a greater area of Ukraine, and the border region of Russia. However, predictions of suitability and the potential distribution in these regions varied among the six correlative modeling algorithms, which indicates model uncertainty (Figs S3 and S4, Supporting information). For example, the Gaussian process and support vector machine algorithms predicted a larger extent of climatically suitable area in eastern Europe than other algorithms.

Temperature and aridity were both important range-limiting factors for $C p s$ in Europe and western Asia. According to CLIMEX, cold stress is predicted to constrain Cps to latitudes below $c a .60^{\circ} \mathrm{N}$ in Europe, and it would exclude the species from western Russia except for the southernmost regions (Fig. 2B). Conversely, a combination of heat and dry stress in Iran and countries on the eastern edge of the Caspian Sea (e.g., Turkmenistan, Kazakhstan) is predicted to limit the species to predominantly southwestern areas of the Caspian Sea region (Figs 2C, D).

Heat and dry stress are also predicted to exclude $C p s$ from most of southern Spain and surrounding non-coastal areas of northwestern Africa. Employing the irrigation option in CLIMEX resulted in increases in climatic suitability along the species' predicted range throughout Europe and western Asia (Fig. 1B), which subsequently resulted in an expansion in the potential distribution in northern Europe (Sweden and Finland), southern Europe (e.g., Greece), eastern Europe (Ukraine), western Russia, Turkey, and the Caucasus (e.g., Armenia and Azerbaijan).

\section{Climatic suitability for and potential distribution of $\mathrm{Cps}$ in North America}

Overall, predictions of climatic suitability and the potential distribution estimated by CLIMEX and the ensemble correlative model were concordant for North America (Fig. 3). Both models predicted climatically suitable conditions throughout most of eastern United States, whereas 
404 suitable conditions in the western United States were almost entirely limited to the Pacific coast 405 region (Fig. 3A-C). CLIMEX predicted the highest ecoclimatic and population growth index 406 values in the eastern United States particularly in states along the east coast and Gulf coast (Figs $4073 \mathrm{~A}, 4 \mathrm{~A})$. Several southeastern and midwestern states where Cps is not known to be established 408 were predicted to be climatically suitable for this pathogen. These include Arkansas, Missouri, 409 Illinois, and Indiana. In the western United States and southern British Columbia, the potential 410 distribution included western Oregon and Washington, coastal areas of California and southern 411 British Columbia, the Sierra Nevada Mountain range (California), and a small area of the 412 northern Rocky Mountains in Idaho and British Columbia. Major portions of the Great Plains, 413 Intermountain West and Southwest were excluded from the potential distribution even in the 414 CLIMEX model that included summer irrigation (Fig. 3B, D). The northernmost parts of the 415 potential distribution were limited to coastal areas of the Pacific (British Columbia) and Atlantic 416 (Quebec, Novia Scotia, and New Brunswick).

417 The ensemble correlative model predicted a somewhat larger potential distribution for 418 Cps in eastern North America than the CLIMEX model. Specifically, it included more inland 419 parts of the Southeast and higher latitude parts of the Northeast and southern Canada (Fig. 3D). 420 For example, the potential distribution extended farther west in the southeastern United States 421 and included eastern Texas and Oklahoma, and it extended farther north in eastern North 422 America and included all northeastern states and southern Quebec and Ontario. Predictions of 423 climatic suitability and presence for these areas were mostly consistent across individual 424 correlative modeling algorithms (Figs S4 and S5, Supporting information). According to CLIMEX, cold stress was the primary range-limiting factor for Cps in 426 North America (Fig. 4B), although arid conditions in the Intermountain West and hot 427 temperatures in the South limited the pathogen's distribution in those areas (Figs 4C, D). Cold 428 stress excluded the species from high-elevation areas in the Intermountain West (most of the 429 Rocky Mountains), from northern parts of the Northeast (northern New York and most of 430 Vermont, New Hampshire, and Maine) and the Midwest (most of Wisconsin and all of North 431 Dakota, South Dakota, and Minnesota), and from Canada and Alaska except for some coastal 432 areas of the Pacific. Estimates of population growth for North America (Fig. 4A) indicate that 433 Cps populations could grow in several areas which were excluded by cold stress, a finding which 434 suggests that populations could at least temporarily establish during favorable seasons. For 
435

436

437

438

439

440

441

442

443

444

445

446

447

448

449

450

451

452

453

454

455

456

457

458

459

460

461

462

463

464

465

example, population growth was high in Wisconsin, New England, and southern parts of Ontario and Quebec; however, cold stress is predicted to prevent overwintering survival throughout most of these areas. Similarly, heat stress contributed to the exclusion of $C p s$ in eastern Texas despite high population growth rates. Population growth and survival were both low across the Intermountain West primarily due to insufficient moisture, and heat stress and dry stress contributed to exclusion of the pathogen from much of the Southwest including western Texas.

Employing the irrigation option in CLIMEX resulted in increases in climatic suitability throughout much of the western United States (Fig. 3B); however, increases were insufficient for the inclusion of the Intermountain West and Southwest in the potential distribution.

\section{Global climatic suitability for and potential distribution of $\mathrm{Cps}$}

Ensemble correlative model projections at a global scale were only partially consistent with the CLIMEX model (Figs 5 and 6). Both modeling approaches predicted highly suitable conditions in New Zealand, where Cps has been reported on both the North and South Island (Appendix 1, Supporting information), and throughout southeastern China, Japan, southern Australia, South Africa (coastal areas), Uruguay, and parts of Brazil, Argentina, Paraguay, and southern Chile (Fig. 5). Additionally, the ensemble correlative model predicted unsuitable conditions in most of the same areas where CLIMEX predicted unsuitability due to high levels of cold stress (e.g., in northern Asia; Fig. S6, Supporting information). While concordant predictions of climatic suitability for these regions translated to broad overlap in estimates of the potential distribution (Fig. 6), CLIMEX predicted higher climatic suitability and a larger potential distribution in other regions of the world. Model predictions were particularly discordant in equatorial (tropical) regions of South Asia, Africa, and South and Central America. For example, most high elevation areas of Africa and South Asia that were included the potential distribution according to CLIMEX had low or zero climatic suitability in the ensemble correlative model, whereas lower elevation regions that were included in the potential distribution by the ensemble model such as in India and the Indochina peninsula were unsuitable in the CLIMEX model (Fig. 5) due to heat stress (Fig. S6, Supporting information). The MOP analysis of climatic PC predictors used for the ensemble correlative model revealed high levels of similarity in climate between the calibration and projection area in temperate regions of the world (MOP index $\geq 0.9$ ), but dissimilarity was higher in equatorial regions, particularly in parts of Southeast Asia and South 
466

467

468

469

470

471

472

\section{3}

474

475

476

477

478

479

480

America (Fig. 7). This finding indicates that portions of environmental space in equatorial regions may be within the range of individual variables but they represent new combinations of predictors, which suggests that predictions there may be unreliable (Zurell et al. 2012, Owens et al. 2013). Employing the irrigation option in CLIMEX resulted in only marginal increases in the global potential distribution, mostly in coastal areas of arid parts of South America (e.g., Chile and Peru), Africa (e.g., Morocco and Namibia), and southern Australia.

\section{Discussion}

This study used both process-based CLIMEX and correlative models to assess the risk for Cps, a highly invasive plant pathogen, to establish at local, regional and global scales. This assessment can help guide the development of local and regional phytosanitary protocols for preventing further spread of the pathogen, prioritizing global surveillance efforts for more effective early detection, and planning for eradication, containment and management where accidental introductions do occur. These three steps are critical to preventing accidental introductions of Cps to and becoming established in predicted high risk areas where it is not yet present (Daughtrey 2019, Hong 2019b). They are also crucial to preventing boxwood blight from becoming rampant in areas where this invasive pathogen is at its early stages of establishment (Henricot 2006). Cps has spread rapidly, as evidenced by its invasion of 24 countries across three distant regions (Europe and western Asia, New Zealand, and North America) in less than 30 years (Palmer and Shishkoff 2014, LeBlanc et al. 2018, Daughtrey 2019). Preventing its accidental introduction to and establishment in new areas and mitigating its local spread are both pivotal to safeguarding global boxwood crops, plantings, and forests (Daughtrey 2019, Hong 2019b).

All models performed very well and were mostly consistent in their predictions for the calibration area (i.e., Europe, western Asia, and North America). The process-based CLIMEX model correctly predicted climatically suitable conditions at validation localities for $C p s$ in North America and New Zealand, and the six individual correlative models and ensemble model had very high evaluation metrics for the calibration area. Cold temperatures were a major rangelimitation at higher latitudes and elevations, as evidenced by the absence of the species from northern areas which have high levels of cold stress in the CLIMEX model, and by the strong 
497 contribution of the cold-temperature related PC predictor (PC2) to correlative models. Moisture

498 during warm seasons was also a major range limiting factor, as demonstrated by increases in

499 climatic suitability and the potential distribution which occurred when implementing the summer

500 irrigation option in CLIMEX, and by the strong contribution of the PC predictor (PC1) related to

501 warm season moisture and moisture seasonality to correlative models. Hot temperatures, often in

502 combination with arid conditions, play a range-limiting role for Cps predominantly in the

503 southern regions of western Asia (e.g., northern Iran) and in the United States particularly in the

504 Southwest.

Climatic suitability for and potential distribution of $\mathrm{Cps}$ in Europe, western Asia, and North 507 America

508 Some of the highest levels of climatic suitability according to the CLIMEX and ensemble correlative model occurred in western Europe, western Asia (Black and Caspian Sea regions),

510 and the east coast of the United States, a finding which is consistent with the widespread

511 presence of Cps in these regions. Oceanic climates in these areas has probably facilitated the

512 pathogen's invasion because few gaps in precipitation and high humidity over the year combined

513 with warm-to-hot summer temperatures creates conducive conditions for infections (Fig. 8)

514 (Gehesquière 2014, Daughtrey 2019). In the eastern United States, Cps is particularly prevalent

515 in the Mid-Atlantic and northern parts of the Southeast; however, there are relatively few reports

516 of the pathogen from Florida and the Deep South (southernmost states in the Southeast), despite

517 the inclusion of most of these regions in the potential distribution. For example, boxwood blight

518 has not been reported beyond two locations in the Tallahassee area of northern Florida in 2016

519 where contaminated stock plants were received and then eradicated in 2016 (Iriarte et al. 2016),

520 and to date there have been no positive reports for Texas, Louisiana, and Mississippi (Hall 2021).

521 According to CLIMEX, hot temperatures reduced climatic suitability throughout Florida except

522 for along coastlines and from the Deep South except for northern parts of some states (e.g.,

523 northern Alabama and Georgia), which may explain the paucity of reports from these areas.

524 Hagan and Conner (2013) posited that disease development on container or field stock in

525 Alabama would most likely occur during extended periods of wet weather in mid-fall into mid-

526 spring because temperatures would be more ideal for growth than during the summer.

527 Additionally, shade can reduce temperatures and create humid conditions that may create more 
528 favorable conditions for infections in hot environments (Bush et al. 2016, Daughtrey 2019).

529 Additional data on the pathogen's ability to survive prolonged heat, particularly in the more heat-

530 resistant microsclerotia form (Shishkoff and Camp 2016, Miller et al. 2018, Yang and Hong

531 2018), could help resolve whether it may establish in parts of the Deep South which may have

532 ideal growing conditions during cool seasons.

533 Many areas with Mediterranean climates including those in southern Europe and the

534 Pacific coast region of the United States were included in the potential distribution according to

535 both modeling approaches, but $C p s$ has a limited presence in these regions to date. In southern

536 Europe, Cps has been reported on B. sempervirens 'Suffruticosa' in nurseries or gardens from

537 only a handful of localities in northwestern Spain (Pintos Varela et al. 2009), southern France

538 (Saurat et al. 2012), northern Italy (Saracchi et al. 2008), and Croatia (Cech et al. 2010). The

539 pathogen has seemingly had opportunities to invade southern Europe given its rapid expansion

540 throughout other parts of the continent beginning in ca. 1994 (LeBlanc et al. 2018, Daughtrey

541 2019). Host availability is likely not an issue because boxwood is commonly grown in gardens

542 and landscapes throughout southern Europe, and native populations of $B$. sempervirens and $B$.

543 balearica occur in pockets in northern Africa (Morocco and Algeria), central France, the

544 southern European peninsulas (Iberian, Italian and Balkan), certain Mediterranean Islands, and

545 Turkey (Di Domenico et al. 2012, Caudullo et al. 2017). In the western United States, Cps has

546 been documented only in a handful of locations in western Oregon and the San Francisco Bay

547 area despite having a potential distribution which encompasses Mediterranean climates

548 throughout the region, including the entire California coast, parts of the Sierra Nevada Mountain

549 range, and areas west of the Cascade Mountains in Oregon and Washington. Long warm-to-hot

550 dry summers and cool wet winters which characterize Mediterranean climates may hinder long-

551 term establishment of Cps because optimal conditions for growth that transpire during warm and

552 wet weather occur too infrequently (Fig. 8). Applying the summer irrigation option in the

553 CLIMEX model resulted in an increase in suitability throughout southern Europe and areas with

554 Mediterranean climates in the western United States, a finding which is consistent with

555 observations that outbreaks in Oregon and California are often associated with summer irrigation

556 (J. Weiland, pers. comm.) or unusually wet spring and summers (Blomquist et al. 2018). Thus,

557 regions with Mediterranean climate will likely be at higher risk of establishment if boxwood is

558 irrigated during periods of optimal temperatures for Cps development, or during relatively wet 
years. Overhead irrigation in particular facilitates boxwood blight outbreaks because it creates

560 higher relative humidity and exposes leaf surfaces to longer periods of wetness (Gehesquière

561 2014, Bartíková et al. 2020b, 2020a).

562 Climatic suitability tended to be lower in regions with humid continental climates

563 compared to those with oceanic climates, despite the inclusion of many of these areas in the

564 potential distribution. In humid continental parts of Europe, which includes most of eastern

565 Europe and parts of Ukraine and Russia, optimal conditions for infections (warm and wet

566 weather) may occur too infrequently owing to long, cold winters and warm-to-hot, dry summers.

567 The only reports of the pathogen from these regions have come from nurseries and gardens in the

568 Czech Republic (Safránková et al. 2012, Bartíková et al. 2020a) and a single nursery in western

569 Ukraine (Matsiakh 2016). The common element of diseased boxwood in gardens in the Czech

570 Republic was the use of irrigation systems or partial-shade conditions, which created higher

571 humidity and exposed leaves longer periods of wetness (Bartíková et al. 2020a). Implementing

572 the summer irrigation option in CLIMEX increased suitability throughout central and eastern

573 Europe and resulted in an expansion of the potential distribution in western Russia, Ukraine,

574 Turkey and the Caucasus, which provides additional evidence that irrigation will likely increase

575 the risk of establishment of $C p s$ in these regions.

576 As with Europe, climatic suitability tended to be lower in humid continental regions of

577 North America that were included in the potential distribution; however, cool temperatures rather

578 than aridity likely explain this finding. According to CLIMEX, cold stress lowered climatic

579 suitability throughout much of non-coastal New York, New England, and southeastern Canada,

580 which is consistent with an absence of Cps from these areas and with lower suitability predicted

581 by the ensemble correlative model. In the midwestern United States, $C p s$ has a limited presence

582 despite the growing number of reports of the pathogen for this region, including from Missouri

583 (2014), Kansas (2014), Illinois (2016), Indiana (2018), Arkansas (2019), Michigan (2018), and

584 Wisconsin (2018). Nevertheless, economic damages to the horticultural industry in the Midwest

585 could be significant if Cps takes hold because this region is one of the top four regions in inter-

586 regional trade of boxwood (Hall et al. 2021), which supports the need for boxwood producers

587 and users to be vigilant in watching for infections and quickly eradicating the pathogen when it is

588 found (Hong 2019a). Our models indicate that cold temperatures will likely prevent

589 establishment in northern Minnesota, northern Wisconsin, most of Nebraska, North Dakota, and 
590 South Dakota. Cps was found in North Dakota in 2019 on contaminated stock plants that were 591 received from Ohio, but it has not been found in landscape settings where it could potentially be 592 exposed to winter conditions (Charles Elhard, pers. comm.). Future outbreak reports from areas 593 which are predicted to be too cold for establishment should be followed closely to assess the 594 ability of Cps to overwinter. For example, soil or snow cover may offer protection to overwintering microsclerotia that may allow the pathogen to survive in areas which are predicted to be unsuitable by our models.

Areas of Europe, western Asia, and North America which have arid or semi-arid climates had some of the lowest levels of climatic suitability, and will therefore be at relatively low risk of establishment at least in the absence of supplemental moisture. Range expansion of Cps in northern Europe and Russia will likely be prevented by cold temperatures; however, aridity often combined with hot temperatures may play a large role in limiting the pathogen's expansion at its

602 eastern range edge (Caspian Sea region) and southern range edge (Spain, Turkey and the Caspian

603 Sea region). In North America, cold temperatures were predicted to exclude Cps from most of 604 western Canada and the Rocky Mountains region; however, aridity in the Intermountain West 605 and Southwest played the most significant role in restricting the pathogen's potential distribution 606 in the western United States. Implementing the irrigation option in CLIMEX did not appreciably 607 increase climatic suitability in the Intermountain West or Southwest, which suggests that 608 infections there may only be possible in highly irrigated settings, and potentially in shaded areas 609 during the hot season. With the exception of New Mexico, states in these regions have low 610 rankings for production and total sales of boxwood (Hall et al. 2021), which could further limit 611 the chance for Cps to establish there. Global climatic suitability for and potential distribution of $\mathrm{Cps}$ Maps of climatic suitability and the potential distribution for Cps indicate that most 615 regions of the world where Buxus and its congeners (Didymeles, Haptanthus, Pachysandra, 616 Sarcococca, and Styloceras) are native are at risk of establishment. Most of the Buxaceae species 617 are tropical or subtropical, with native ranges that include western and southern Europe, 618 southwest, southern and eastern Asia, Africa, Madagascar, northernmost South America, Central 619 America, Mexico and the Caribbean (Köhler and Brückner 1989, Balthazar et al. 2000, Köhler 620 2014). The CLIMEX and ensemble correlative models included much of eastern Asia and the 
621 Himalayas in the potential distribution, which are home to $c a .40$ species of Buxus (Köhler and 622 Brückner 1989), four species of Pachysandra, and 11 species of Sarcococca (Balthazar et al.

623 2000). According to CLIMEX, the potential distribution in the Neotropics included the Andes

624 region, where all five species of Styloceras Kunth ex A. Juss. are endemic (Balthazar et al.

625 2000), and it overlapped with at least some of the ca. 50 species of Buxus native to Central

626 America and the Caribbean, such as in Mexico, Guatemala, Cuba, Hispaniola, and Puerto Rico

627 (Köhler and Brückner 1989, Gutiérrez 2014, Köhler 2014). For Africa, both modeling

628 approaches included a narrow band of the South African coast which has endemic Buxus (Friss

629 1989) in the potential distribution, and CLIMEX included additional areas where Buxus species

630 occur including in Madagascar (nine species) (Schatz and Lowry 2002) and in western and

631 eastern Africa (e.g., in Ethiopia, Kenya, Tanzania, and Angola)(Friss 1989). An overall lack of

632 comprehensive and current maps that depict the ranges of Buxaceae species hinders making

633 detailed assessments into the extent of overlap with the potential distribution of Cps.

634 Nonetheless, our broad-scale assessment indicates the potential for the pathogen to expand its

635 range globally.

636 Preventing the establishment of Cps in regions with native boxwood is important because

637 the pathogen can clearly cause ecological damage to affected ecosystems. Studies of Cps in

638 native stands of B. sempervirens subsp. colchica in Georgia and B. sempervirens subsp. hyrcana

639 in the Caspian Hyrcanian forests of northern Iran revealed rapid and intensive defoliation of

640 boxwood plants of different ages, with complete defoliation occurring in up to $90 \%$ of some

641 populations in just one year after positive detection of boxwood blight (Mirabolfathy 2013,

642 Matsiakh 2016). Infected plants are also vulnerable to attacks by secondary opportunistic

643 pathogens that can lead to eventual death (Matsiakh 2016). A literature survey showed that a loss

644 of native boxwood in Europe and the Caucasus could lead to reductions in soil stability and

645 subsequent declines in water quality and flood protection, and to declines in Buxus-associated

646 biodiversity including at least 63 potentially obligate species of lichens, fungi, chromista and

647 invertebrates (Mitchell et al. 2018). Currently there is no effective control for boxwood blight in

648 forests because removing infected plants or applying fungicides across large areas is infeasible

649 (Matsiakh 2016, Patarkalashvili 2017). Early detection of Cps will therefore be the most

650 economical and effective method to prevent additional invasions in areas with susceptible native

651 species. 
The invasion of Cps could be particularly devastating to species which are vulnerable

653 both in terms of their conservation status and their susceptibility to infection. Many Buxus

654 species are already threatened or endangered because of small and isolated distributions resulting

655 from natural causes such as island endemism and post-glacial climate change (Di Domenico et

656 al. 2012, Gutiérrez 2014), anthropogenic disturbances such as deforestation and over-harvesting

657 of wood (Mitchell et al. 2018), and invasions of non-native pests such as the box tree moth

658 Cydalima perspectalis (Walker, 1859) in Europe and western Asia (Matsiakh 2016,

659 Patarkalashvili 2017, Matsiakh et al. 2018, Panahi et al. 2021). For example, most of the Buxus

660 species native to tropical America are endemic to single islands in the Caribbean (Köhler and

661 Brückner 1989), 37 of which occur in Cuba alone (Gutiérrez 2014, Köhler 2014). None of the

662 Buxaceae species tested to date are completely immune to boxwood blight infections, although

663 severity of disease varies widely across Buxus species and cultivars (Henricot et al. 2008,

664 Shishkoff et al. 2015, LaMondia and Shishkoff 2017), and it appears to be low in pachysandra

665 (Pachysandra) and sweet box species (Sarcococca) species (Ryan et al. 2018, Kong and Hong

666 2019). Susceptible species which have at least partially overlapping native ranges with the

667 potential distribution of Cps include B. sempervirens and subspecies (southern Europe and the

668 Black and Caspian Sea regions), B. balearica (Mediterranean basin), B. bodinieri (China), B.

669 glomerata (Cuba and Hispaniola), B. harlandii (China to Vietnam), B. macowanii (South

670 Africa), B. riparia (Japan), B. wallichiana (Himalayas from east Afghanistan to Nepal), at least

671 three Pachysandra species including the endangered P. procumbens (eastern United States), and

672 several Sarcococca species (East Asia). More studies on the susceptibility of Buxaceae species to

673 infection are needed to better assess the risk of the pathogen establishing and causing ecological

674 harm.

675 Our global climatic suitability models for Cps provide some of the first insights into the

676 potential geographic origin of the pathogen, which is still unknown (Castroagudín et al. 2020a,

677 LeBlanc et al. 2021). The CLIMEX and ensemble correlative model both included a large part of

678 southeastern China and Japan in the potential distribution, a finding which supports the

679 hypothesis that the pathogen may have arrived to Europe on boxwood plants from East Asia

680 (Daughtrey 2019). A possible origin of Cps from China is consistent with reports that most non-

681 European imports of Buxus species to Europe come from this country (EPPO 2012), and with a

682 leading hypothesis for the likely origin of invasive box tree moth in Europe (Van der Straten and 
683 Muus 2010, CABI 2021). Nonetheless, we cannot rule out the possibility that Cps is native to

684 another host center of diversity for Buxus or other Buxaceae species such as in the Caribbean or

685 Madagascar (Castroagudín et al. 2020a), particularly given that at least one of the modeling

686 approaches included parts of these regions in the potential distribution.

Model uncertainty

Discordance between CLIMEX and ensemble correlative model predictions for Cps in Europe, western Asia, and North America primarily occurred at the predicted range edges. The potential distribution according to the ensemble correlative model extended somewhat farther north in Europe and the eastern United States, and farther east in the southeastern United States.

693 Conversely, the potential distribution according to CLIMEX extended slightly farther east in

694 Europe and included the border region of Russia. However, ensemble correlative model

695 predictions for areas of discordance with CLIMEX should be interpreted with caution because

696 predictions also varied among the six different correlative models, which indicates uncertainty

697 both across and within modeling approaches (i.e. process-based vs. correlative models and

698 correlative vs. correlative models). These findings are consistent with studies showing that model

699 type is a primary source of uncertainty when predicting species distributions, and that uncertainty

700 is often greater at range margins compared with range cores (Marmion et al. 2009, Capinha and

701 Anastácio 2011, Vale et al. 2014, Watling et al. 2015, Shabani et al. 2016).

702 Global projections of the ensemble correlative model were particularly discordant with

703 the CLIMEX model for equatorial regions. We focused more on interpreting CLIMEX model

704 predictions for equatorial regions because the MOP analysis indicated that dissimilarity in

705 climate for the calibration and projection area was highest for equatorial areas, which suggests

706 that predictions there may be unreliable (Zurell et al. 2012, Owens et al. 2013, Higgins et al.

707 2020). Process-based models such as CLIMEX are thought to be more reliable in predicting a

708 species' potential distribution in novel climates than correlative models because they rely on

709 proximate constraints limiting distributions, rather than on model extrapolations (Kearney and

710 Porter 2009, Evans et al. 2016, Higgins et al. 2020). For example, most equatorial areas that were

711 included in the potential distribution by the ensemble correlative model were predicted to be

712 excluded by heat stress in the CLIMEX model, including those in central Africa, India, and

713 mainland Southeast Asia (Indochina and Malay peninsulas). Heat stress is measured using 
714 thresholds and rates that were calibrated using ecophysiological information and records for the

715 pathogen in the hottest parts of its known distribution, and its predicted role in shaping the

716 potential distribution of Cps seems realistic given present-day knowledge of the species. As the

717 occurrence record dataset for model fitting influences projections into new areas, future work

718 should investigate whether Cps has persisted at localities used to fit correlative models for this

719 study (Appendix S1, Supporting information), particularly in newly invaded areas such as those

720 in the southern, midwestern, and Pacific coast region of North America. Records from newly

721 invaded areas could potentially represent short-term establishments, such as during a year(s) with

722 favorable weather, and may therefore be excluded from future presence-only correlative

723 modeling analyses.

$724 \quad$ Future climate-based risk mapping studies for Cps which use more recent climate data

725 and potentially incorporate inter-annual variability into models may provide more robust

726 estimates of present-day risk. Our models used historical 30-year climate normals for 1961 to

7271990 because the current version of CLIMEX has no native ability to import and process other

728 forms of gridded data, such as climate normals for a more recent time frame (e.g., 1991-2021).

729 Additionally, CliMond data for more recent time frames have not been developed to our

730 knowledge, which hinders making a comparison of correlative models based on the same set of

731 climate predictors for different time frames. Global temperatures and precipitation patterns have

732 significantly changed even over the past 30 years (USGCRP 2018, IPCC 2021), which suggests

733 that climatic suitability models for Cps could misrepresent establishment risk in areas where

734 climates have become more (or less) favorable for the pathogen's growth and survival. For

735 example, higher minimum winter temperatures or decreased frequency or intensity of extreme

736 cold resulting from climate change may increase rates of overwintering survival for invasive

737 microbial pathogens (Dukes et al. 2009, Thakur et al. 2019), which raises the possibility that

738 establishment risk at the northernmost range edges of Cps may be higher than our models

739 predict. Additionally, increasing humidity, precipitation, and rising temperatures in certain

740 regions such as the midwestern United States (USGCRP 2018, IPCC 2021) could increase risk of

741 establishment, whereas aridification in regions such as southern Europe, western and central

742 Asia, and western North America (IPCC 2021) may reduce risk. Climate suitability models

743 which account for inter-annual variations may increase the accuracy of predictions for Cps under

744 climate change because biologically relevant climatic variation that can arise from events such as 
745 droughts or heat waves may be obscured in aggregated climate datasets such as 30-year climate 746 normals (Gardner et al. 2021).

Conclusions

In developing species distribution models for $C p s$ and evaluating the role of climatic factors in shaping its known range limits, we have provided some of the first insights into the potential invasive distribution and geographic origin of the most widespread and damaging pathogens of boxwood. Understanding where the pathogen could establish is particularly important in light of evidence for intercontinental dispersal and multiple introductions of Cps in the United States, which suggests that introductions of the pathogen are common and will likely continue to occur (Castroagudín et al. 2020a, LeBlanc et al. 2021). The CLIMEX and ensemble correlative model are consistent in predicting the potential for further spread in Europe (southern and eastern Europe), and in North America (southern, midwestern, and Pacific coast region). While our models can assist with identifying areas to watch for Cps both regionally and globally, an assessment of local climates for a target area may provide greater insight into the likelihood of the establishment. For example, the pathogen's limited presence in areas of the potential distribution in Europe and North America which have Mediterranean and humid continental

762 climates may suggest that regions of the global potential distribution with similar climates are at

763 lower risk of establishment. Locations which are climatically marginal for Cps, but which have

764 extensive boxwood plantings, may be best able to exclude or eradicate boxwood blight outbreaks

765 by implementing best practices such as using less dense plantings, limiting shade cover, and 766 exclusively make use of underground irrigation (Bush et al. 2016, Dart et al. 2016, Daughtrey 767 2019). Additionally, the avoidance of highly susceptible cultivars including Buxus sempervirens 768 'Suffruticosa' and Buxus sempervirens (Shishkoff et al. 2015; LaMondia and Shishkoff 2017;

769 LeBlanc et al. 2018; Kramer et al. 2020) may help reduce the risk of establishment. Surveillance 770 of Cps in regions of the world that fall within the potential distribution of the pathogen and have 771 native Buxaceae species will be key for early detection and rapid responses measures.

773 may provide better insights into potential range limits for $C p s$, such as in high-elevation or high-

774 latitude areas where the pathogen may now be capable of survival due to warming temperatures

775 in recent decades. The CLIMEX model developed for this study could be modified to predict the 
776 potential distribution of $C$. henricotiae, a closely related but genetically distinct species that also

777 causes boxwood blight (Gehesquière et al. 2016, LeBlanc et al. 2021). To date $C$. henricotiae has

778 only been found in five countries in Europe, but further range expansion of this pathogen is

779 expected and would likely influence boxwood blight epidemiology in the landscape because its

780 thermotolerance is greater than Cps (Miller et al. 2018, LeBlanc et al. 2021).

781

782

\section{Data availability}

784 The data, metadata, code, and derived products to reproduce the analysis and figures have been

785 archived at Zenodo (https://doi.org/XX.XXXX/zenodo.XXXXXXX).

786

787 Funding

788 This work was funded by USDA APHIS Cooperative Agreement No. 20-8130-0282-CA. 789

\section{Competing interests}

791 The authors have declared that no competing interests exist.

792

\section{Acknowledgements}

794 We extend our thanks to Thomas Brand, Manus Gammelgard, Iryna Matsiakh, Nicole Ward-

795 Gauthier, Fulya Baysal-Gurel, Funda Oskay, and Jerry Weiland for providing geographic

796 location information for Cps occurrence records. 


\section{References}

798 Aiello-Lammens ME, Boria RA, Radosavljevic A, Vilela B, Anderson R. (2015) spThin: an R package for spatial thinning of species occurrence records for use in ecological niche models. Ecography 38: 541-545. https://doi.org/https://doi.org/10.1111/ecog.01132

Akili S, Katircioglu YZ, Zor K, Maden S (2012) First report of blight on Buxus spp. caused by Cylindrocladium pseudonaviculatum in the Eastern Black Sea region of Turkey. Plant Disease 87: 1539. https://doi.org/10.1094/PDIS.2003.87.12.1539A

Allouche O, Tsoar A, Kadmon R (2006) Assessing the accuracy of species distribution models: prevalence, kappa and the true skill statistic (TSS). Journal of Applied Ecology 43: 12231232. https://doi.org/10.1111/j.1365-2664.2006.01214.x

de Andrade AFA, Velazco SJE, De Marco Júnior P (2020) ENMTML: An R package for a straightforward construction of complex ecological niche models. Environmental Modelling and Software 125: 104615. https://doi.org/10.1016/j.envsoft.2019.104615

Anonymous (2012) New plant disease - boxwood blight. Tillamook County Tiller: 1.

Avenot HF, King C, Edwards TP, Baudoin A, Hong CX (2017) Effects of inoculum dose,

Balthazar M von, Endress PK, Qiu YL (2000) Phylogenetic relationships in Buxaceae based on nuclear internal transcribed spacers and plastid ndhF sequences. International Journal of Plant Sciences 161: 785-792. https://doi.org/10.1086/314302

Bartíková M, Brand T, Beltz H, Šafránková I (2020b) Host susceptibility and microclimatic

Bartíková M, Holková L, Šafránková I (2020a) Occurrence of boxwood blight (Calonectria pseudonaviculata and C. henricotiae) in historical gardens in the Czech Republic. European Journal of Plant Pathology 158: 135-142. https://doi.org/10.1007/s10658-020-02061-2 conditions influencing the development of blight diseases caused by Calonectria henricotiae. European Journal of Plant Pathology 157: 103-117. https://doi.org/10.1007/s10658-020-01986-y

Batdorf L (2005) Boxwood Handbook-A Practical Guide to Knowing and Growing Boxwood. 3rd ed. The American Boxwood Society, Boyces, Virginia, USA, 123 pp.

Beaumont L, Gallagher R, Thuiller W, Downey P, Leishman M, Hughes L (2009) Different 
climatic envelopes among invasive populations may lead to underestimations of current and future biological invasions. Diversity and Distributions 15: 409-420. https://doi.org/10.1111/j.1472-4642.2008.00547.x

Blomquist CL, Kosta KL, Santos PF, Rooney-Latham S (2018) First report of boxwood blight caused by Calonectria pseudonaviculata in California. Plant Disease 102: 2379-2379. https://doi.org/https://doi.org/10.1094/PDIS-05-18-0765-PDN

Boyce MS, Vernier PR, Nielsen SE, Schmiegelow FKA (2002) Evaluating resource selection functions. Ecological Modelling 157: 281-300. https://doi.org/https://doi.org/10.1016/S0304-3800(02)00200-4

Bush E, Hansen MA, Dart N, Hong C, Bordas A, Likins TM (2016) Best management practices for boxwood blight in the Virginia home landscape. Virginia Cooperative Extension Publication PPWS-85NP. Virginia Tech, VA. Online: https://vtechworks.lib.vt.edu/bitstream/handle/10919/80658/PPWS-29.pdf.

CABI (2021) Cydalima perspectalis (box tree moth). Invasive Species Copendium. Wallingford, UK: CAB International. www.cabi.org/isc.

Capinha C, Anastácio P (2011) Assessing the environmental requirements of invaders using ensembles of distribution models. Diversity and Distributions 17: 13-24. https://doi.org/10.1111/j.1472-4642.2010.00727.x

Castroagudín VL, Weiland JE, Baysal-Gurel F, Cubeta MA, Daughtrey ML, Gauthier NW, LaMondia J, Luster DG, Hand FP, Shishkoff N, Williams-Woodward J, Yang X, LeBlanc $\mathrm{N}$, Crouch JA (2020a) One clonal lineage of Calonectria pseudonaviculata is primarily responsible for the boxwood blight epidemic in the United States. Phytopathology 110: 1845-1853. https://doi.org/10.1094/PHYTO-04-20-0130-R

Castroagudín VL, Yang X, Daughtrey ML, Luster DG, Pscheidt JW, Weiland JE, Crouch JA (2020b) Boxwood blight disease: A diagnostic guide. Plant Health Progress 21: 291-300. https://doi.org/10.1094/PHP-06-20-0053-DG

Caudullo G, Welk E, San-Miguel-Ayanz J (2017) Chorological maps for the main European woody species. Data in Brief 12: 662-666. https://doi.org/10.1016/j.dib.2017.05.007

Cech T, Diminic D, Heungens K (2010) Cylindrocladium buxicola causes common box blight in Croatia. Plant Pathology 59: 1169-1169. https://doi.org/10.1111/j.1365-3059.2010.02332.x Cobos ME, Townsend Peterson A, Barve N, Osorio-Olvera L (2019) kuenm: an R package for 
detailed development of ecological niche models using Maxent. PeerJ 7: e6281. https://doi.org/10.7717/peerj.6281

Cooper JC, Soberón J (2018) Creating individual accessible area hypotheses improves stacked species distribution model performance. Global Ecology and Biogeography 27: 156-165. https://doi.org/10.1111/geb.12678

Crous PW, Groenewald JZ, Hill CF (2002) Cylindrocladium pseudonaviculatum sp. nov. from New Zealand, and new Cylindrocladium records from Vietnam. Sydowia 54: 23-34.

Dart N, Hong C, Craig CA, Fry JT, Hu X (2015) Soil inoculum production, survival, and infectivity of the boxwood blight pathogen, Calonectria pseudonaviculata. Plant Disease 99: 1689-1694. https://doi.org/10.1094/PDIS-12-14-1245-RE

Dart N, Hong C, Bordas A, Bush E, Hansen M, Likins T (2016) Best management practices for boxwood blight in Virginia retail nurseries WITHOUT boxwood blight. Virginia Cooperative Extension Publication No. PPWS-35NP. Available at:

http://pubs.ext.vt.edu/PPWS/PPWS-35/PPWS-35.html.

Daughtrey ML (2019) Boxwood blight: threat to ornamentals. Annual Review of Phytopathology 57: 189-209. https://doi.org/10.1146/annurev-phyto-082718-100156

Di Domenico F, Lucchese F, Magri D (2012) Buxus in Europe: Late Quaternary dynamics and modern vulnerability. Perspectives in Plant Ecology, Evolution and Systematics 14: 354362. https://doi.org/10.1016/j.ppees.2012.07.001

Dormann CF, Schymanski SJ, Cabral J, Chuine I, Graham C, Hartig F, Kearney MR, Morin X, Römermann C, Schröder B, Singer A (2012) Correlation and process in species distribution models: Bridging a dichotomy. Journal of Biogeography 39: 2119-2131. https://doi.org/10.1111/j.1365-2699.2011.02659.x

Dormann CF, Elith J, Bacher S, Buchmann C, Carl G, Carré G, Marquéz JRG, Gruber B, Lafourcade B, Leitão PJ, Münkemüller T, McClean C, Osborne PE, Reineking B, Schröder B, Skidmore AK, Zurell D, Lautenbach S (2013) Collinearity: a review of methods to deal with it and a simulation study evaluating their performance. Ecography 36: 027-046. https://doi.org/10.1111/j.1600-0587.2012.07348.x

Douglas SM (2012) Boxwood blight - a new threat to boxwood in the U.S. CNLA/CGGA Winter Symposium, Plantsville, CT. Available at: https://nationalplantboard.org/wpcontent/uploads/docs/2012_meeting/npb_2012_bwb.pdf (Accessed July 27, 2021). 
Dukes JS, Jennifer Pontius, David Orwig, Jeffrey RG, Vikki LR, Nicholas Brazee, Barry Cooke, Kathleen AT, Erik ES, Robin Harrington, Joan Ehrenfeld, Jessica Gurevitch, Manuel Lerdau, Kristina Stinson, Robert Wick, Matthew Ayres (2009) Responses of insect pests, pathogens, and invasive plant species to climate change in the forests of northeastern North America: What can we predict? Canadian Journal of Forest Research 39: 231-248.

Elmhirst JF, Auxier BE, Wegener LA (2013) First report of box blight caused by https://doi.org/10.1139/X08-171

Elith J, Graham CH (2009) Do they? How do they? WHY do they differ? On finding reasons for differing performances of species distribution models. Ecography 32: 66-77. https://doi.org/10.1111/j.1600-0587.2008.05505.x

Elith J, Leathwick JR, Hastie T (2008) A working guide to boosted regression trees. The Journal of animal ecology 77: 802-13. https://doi.org/10.1111/j.1365-2656.2008.01390.x Cylindrocladium pseudonaviculatum in British Columbia, Canada. Plant Disease 97: 559. https://doi.org/https://doi.org/10.1094/PDIS-10-12-0927-PDN

EPPO (2012) EPPO study on the risk of imports of plants for planting, 1061. Paris, France: www.eppo.int/QUARANTINE/EPPO_Study_on_Plants_for_planting.pdf.

EPPO (2020) Calonectria pseudonaviculata (CYLDBU). Available at: http://https://gd.eppo.int/taxon/CYLDBU/distribution (Accessed 2021 May 5).

Evans J. (2021) spatialEco. R package Version 1.3-6. https:/github.com/jeffreyevans/spatialEco. Evans MEK, Merow C, Record S, McMahon SM, Enquist BJ (2016) Towards process-based range modeling of many species. Trends in Ecology and Evolution 31: 860-871. https://doi.org/10.1016/j.tree.2016.08.005

Fisher MC, Henk DA, Briggs CJ, Brownstein JS, Madoff LC, McCraw SL, Gurr SJ (2012) Emerging fungal threats to animal, plant and ecosystem health. Nature 484: 186-194. https://doi.org/10.1038/nature10947

França S, Cabral HN (2019) Distribution models of estuarine fish species: the effect of sampling bias, species ecology and threshold selection on models' accuracy. Ecological Informatics 51: 168-176. https://doi.org/10.1016/j.ecoinf.2019.03.005

Friss I (1989) A synopsis of the Buxaceae in Africa south of the Sahara. Kew Bulletin 44: 293299. 
921 Gardner AS, Gaston KJ, Maclean IMD (2021) Accounting for inter-annual variability alters 922 long-term estimates of climate suitability. Journal of Biogeography 48: 1960-1971.

923 https://doi.org/10.1111/jbi.14125

924 Gasich EL, Kazartsev IA, Gannibal PB, Koval AG, Shipilova NP, Khlopunova LB,

925 Ovsyannikova EI (2013) Calonectria pseudonaviculata - a new for Abkhazia species, the causal agent of boxwood blight. Mikologiya I Fitopatologiya 47: 129-131.

927 Gehesquière B (2014) Cylindrocladium buxicola nom. cons. prop. (syn. Calonectria

928 pseudonaviculata) on Buxus: molecular characterization, epidemiology, host resistance and fungicide control. PHD Thesis. Ghent University (Ghent, Belgium)

930 Gehesquière B, D’Haeyer S, Pham KTK, Van Kuik AJ, Maes M, Höfte M, Heungens K (2013) qPCR assays for the detection of Cylindrocladium buxicola in plant, water, and air samples. Plant Disease 97: 1082-1090. https://doi.org/10.1094/PDIS-10-12-0964-RE

Gehesquière B, Crouch JA, Marra RE, Van Poucke K, Rys F, Maes M, Gobin B, Höfte M, pathogen Calonectria pseudonaviculata, introducing Calonectria henricotiae sp. nov. Plant Pathology 65: 37-52. https://doi.org/10.1111/ppa.12401

Golding N, Purse BV (2016) Fast and flexible Bayesian species distribution modelling using Gaussian processes. Methods in Ecology and Evolution 7: 598-608. https://doi.org/10.1111/2041-210X.12523

Gorgiladze L, Meparishvili G, Sikharulidze Z, Natsarishvili K, Davitadze R (2011) First report of Cylindrocladium buxicola in Georgia. Plant Disease 23: 24.

https://doi.org/10.1094/PDIS-93-6-0670B

Guisan A, Edwards TC, Hastie T (2002) Generalized linear and generalized additive models in

950 Caribbean. PHD Thesis. Free University of Berlin (Berlin, Germany)

951 Hall C (2021) Observations regarding the value of boxwood sales from 2014 to 2019. Boxwood 
Blight Insight Group Newsletter 2: 1-2.

Hall CR, Hong C, Gouker FE, Daughtrey M (2021) Analyzing the structural shifts in U.S. boxwood production due to boxwood blight. Journal of Environmental Horticulture 39: 9199. https://doi.org/10.24266/0738-2898-39.3.91

Hao T, Elith J, Lahoz-Monfort JJ, Guillera-Arroita G (2020) Testing whether ensemble modelling is advantageous for maximising predictive performance of species distribution models. Ecography 43: 549-558. https://doi.org/10.1111/ecog.04890

Henricot B (2006) Box blight rampages onwards. The Plantsman: 153-157.

Henricot B, Pérez Sierra A, Prior C (2000) A new blight disease on Buxus in the UK caused by the fungus Cylindrocladium. Plant Pathology 49: 805. https://doi.org/10.1046/j.13653059.2000.00508.x

Henricot BB, Culham A (2002) Cylindrocladium buxicola, a new species affecting Buxus spp.,

Hūšang A (1989) Boxtree. Encyclopedia Iranica, Vol. IV, pp. 418-420; available at: and its phylogenetic status. Mycologia 94: 980. https://doi.org/10.1080/15572536.2003.11833155

Higgins SI, Larcombe MJ, Beeton NJ, Conradi T, Nottebrock H (2020) Predictive ability of a process-based versus a correlative species distribution model. Ecology and Evolution 10: 11043-11054. https://doi.org/10.1002/ece3.6712

Hijmans RJ, Cameron SE, Parra JL, Jones PG, Jarvis A (2005) Very high resolution interpolated climate surfaces for global land areas. International Journal of Climatology 25: 1965-1978. https://doi.org/10.1002/joc.1276

Hong C (2019a) Fighting pathogens together. Science 365: 229.

https://doi.org/10.1126/science.aay4514

Hong C (2019b) Saving American gardens from boxwood blight. The Boxwood Bulletin 58: 310.

982 IPCC (2021) Climate Change 2021: The Physical Science Basis. Contribution of Working Group 
I to the Sixth Assessment Report of the Intergovernmental Panel on Climate Change. Masson-Delmotte V, Zhai P, Pirani A, Connors SL, Péan C, Berger S, Caud N, Chen Y, Goldfarb L, Gomis MI, Huang M, Leitzell K, Lonnoy E, Matthews JBR, Maycock TK, Waterfield T, O.Yelekçi, Yu R, Zhou B (Eds). Cambridge University Press, Cambridge, U.K.

Ireland KB, Kriticos DJ (2019) Why are plant pathogens under-represented in eco-climatic niche modelling? International Journal of Pest Management 65: 207-216. https://doi.org/10.1080/09670874.2018.1543910

Iriarte F, Paret M, Knox G, Schubert T, Jeyaprakash A, Davison D (2016) First report of boxwood blight caused by Calonectria pseudonaviculata in Florida. Plant Health Progress 17: 229-231. https://doi.org/10.1094/PHP-BR-16-0027

Ivors KL, Lacey LW, Milks DC, Douglas SM, Inman MK, Marra RE, LaMondia JA (2012) First report of boxwood blight caused by Cylindrocladium pseudonaviculatum in the United States. Plant Disease 96: 1070-1070. https://doi.org/10.1094/PDIS-03-12-0247-PDN

Kearney MR, Porter W (2009) Mechanistic niche modelling: Combining physiological and spatial data to predict species' ranges. Ecology Letters 12: 334-350. https://doi.org/10.1111/j.1461-0248.2008.01277.x

Khazaeli P, Rezaee S, Mirabolfathy M, Zamanizadeh H, Kia-daliri SK (2015) Report of boxwood blight extension to Golestan province forests. Applied Entomology and Phytopathology 83: 85-86.

Khazaeli P, Rezaee S, Mirabolfathy M, Zamanizade H, Kiadaliri H (2018) Genetic and phenotypic variation of Calonectria pseudonaviculata isolates causing boxwood blight disease in the Hyrcanian forest of Iran. Agricultural Research \& Technology: Open Access Journal 19: 556081. https://doi.org/10.19080/artoaj.2018.19.556081

Köhler E (2014) Buxaceae. In: Greute W, Rankin-Rodríguez R (Eds), Flora de la República de Cuba. Fasciculo 19(1). Koeltz Scientific Books, Oberreifenberg, Germany, 1-124.

Köhler E, Brückner P (1989) The genus Buxus (Buxaceae): aspects of its differentiation in space and time. Plant Systematics and Evolution 162: 267-283.

Kolganikhina GB (2014) Year dynamics of the Colchis box health status and Cylindrocladium box blight development in the Sochi national park. Russian Journal of Ecology 6: 202-209. Kong P, Hong C (2019) Host responses and impact on the boxwood blight pathogen, Calonectria 
pseudonaviculata. Planta 249: 831-838. https://doi.org/10.1007/s00425-018-3041-4

1015

1016

1017

1018

1019

1020

1021

1022

1023

1024

1025

1026

1027

1028

1029

1030

1031

1032

1033

1034

1035

1036

1037

1038

1039

1040

1041

1042

1043

1044

Kong P, Likins TM, Hong CX (2017) First report of Pachysandra terminalis leaf spot by Calonectria pseudonaviculata in Virginia. Plant Disease 101: 509-509. https://doi.org/https://doi.org/10.1094/PDIS-10-16-1513-PDN

Kramer-Schadt S, Niedballa J, Pilgrim JD, Schröder B, Lindenborn J, Reinfelder V, Stillfried M, Heckmann I, Scharf AK, Augeri DM, Cheyne SM, Hearn AJ, Ross J, Macdonald DW, Mathai J, Eaton J, Marshall AJ, Semiadi G, Rustam R, Bernard H, Alfred R, Samejima H, Duckworth JW, Breitenmoser-Wuersten C, Belant JL, Hofer H, Wilting A (2013) The importance of correcting for sampling bias in MaxEnt species distribution models. Diversity and Distributions 19: 1366-1379. https://doi.org/10.1111/ddi.12096

Kriticos DJ, Maywald GF, Yonow T, Zurcher EJ, Herrmann N, Sutherst RW (2016) CLIMEX Version 4: Exploring the effects of climate on plants, animals and diseases. In: CSIRO, Canberra, Australia. Available at: https://www.hearne.software/getattachment/199e1f3e460a-4ac8-8f7f-1eeee84110c7/Climex-v4-User-Guide.aspx.

Kriticos DJ, Webber BL, Leriche A, Ota N, Macadam I, Bathols J, Scott JK (2012) CliMond: global high-resolution historical and future scenario climate surfaces for bioclimatic modelling. Methods in Ecology and Evolution 3: 53-64. https://doi.org/10.1111/j.2041210X.2011.00134.X

LaMondia JA (2015) Management of Calonectria pseudonaviculata in boxwood with fungicides and less susceptible host species and varieties. Plant Disease 99: 363-369. https://doi.org/10.1094/PDIS-02-14-0217-RE

LaMondia JA, Li DW (2013) Calonectria pseudonaviculata can cause leaf spot and stem blight of Pachysandra procumbens. Plant Health Progress 14: Online. https://doi.org/https://doi.org/10.1094/PHP-2013-0226-01-BR

LaMondia JA, Shishkoff N (2017) Susceptibility of boxwood accessions from the national boxwood collection to boxwood blight and potential for differences between Calonectria pseudonaviculata and C. henricotiae. HortScience 52: 873-879. https://doi.org/10.21273/HORTSCI11756-17

LaMondia JA, Li DW, Marra RE, Douglas SM (2012) First report of Cylindrocladium pseudonaviculatum causing leaf spot of Pachysandra terminalis. Plant Disease 96: 1069. https://doi.org/10.1094/PDIS-03-12-0235-PDN 
1045 Lantschner MV, de la Vega G, Corley JC (2019) Predicting the distribution of harmful species

1046 and their natural enemies in agricultural, livestock and forestry systems: an overview.

1047 International Journal of Pest Management 65: 190-206.

1048 https://doi.org/10.1080/09670874.2018.1533664

1049 LeBlanc N, Salgado-Salazar C, Crouch JA (2018) Boxwood blight: an ongoing threat to

1050 ornamental and native boxwood. Applied Microbiology and Biotechnology 102: 4371-

1051 4380. https://doi.org/10.1007/s00253-018-8936-2

1052 LeBlanc N, Cubeta MA, Crouch JA (2021) Population genomics trace clonal diversification and 1053 intercontinental migration of an emerging fungal pathogen of boxwood. Phytopathology

1054 111: 184-193. https://doi.org/10.1094/PHYTO-06-20-0219-FI

1055 Lehtijärvi A, Doğmuş-Lehtijärvi HT, Oskay F (2017) Boxwood blight in Turkey: impact on

1056 natural boxwood populations and management challenges. Baltic Forestry 23: 274-278.

1057 Leroy B, Delsol R, Hugueny B, Meynard CN, Barhoumi C, Barbet-Massin M, Bellard C (2018)

1058 Without quality presence-absence data, discrimination metrics such as TSS can be

1059 misleading measures of model performance. Journal of Biogeography 45: 1994-2002.

1060 https://doi.org/10.1111/jbi.13402

1061 Leutner B, Horning N (2017) Rstoolbox: tools for remote sensing data analysis. R Package

1062 Version 0.2.6. Available online: https://cran.r-

1063 project.org/web/packages/RStoolbox/index.html.

1064 Li W, Guo Q (2013) How to assess the prediction accuracy of species presence-absence models

1065 without absence data? Ecography 36: 788-799. https://doi.org/10.1111/j.1600-

$1066 \quad 0587.2013 .07585 . x$

1067 Liu C, Berry PM, Dawson TP, Pearson RG (2005) Selecting thresholds of occurrence in the

1068 prediction of species distributions. Ecography 28: 385-393. https://doi.org/10.1111/j.0906-

1069 7590.2005.03957.x

1070 Lombard L, Crous PW, Wingfield BD, Wingfield MJ (2010) Systematics of Calonectria: a

1071 genus of root, shoot and foliar pathogens. Studies in Mycology 66: 1-71.

1072 https://doi.org/10.1016/s0166-0616(14)60020-8

1073 Lovett GM, Weiss M, Liebhold AM, Holmes TP, Leung B, Lambert KF, Orwig DA, Campbell

1074 FT, Rosenthal J, McCullough DG, Wildova R, Ayres MP, Canham CD, Foster DR, LaDeau

1075 SL, Weldy T (2016) Nonnative forest insects and pathogens in the United States: Impacts 
1076

1077

1078

1079

1080

1081

1082

1083

1084

1085

1086

1087

1088

1089

1090

1091

1092

1093

1094

1095

1096

1097

1098

1099

1100

1101

1102

1103

1104

1105

1106

and policy options. Ecological Applications 26: 1437-1455. https://doi.org/10.1890/151176

Magarey RD, Fowler GA, Borchert DM, Sutton TB, Colunga-Garcia M, Simpson JA, Health P, Service I, Colunga-Garcia M (2007) NAPPFAST: an internet system for the weather-based mapping of plant pathogens. Plant Disease 91: 336-345. https://doi.org/10.1094/PDIS-91-40336

Malapi-Wight M, Salgado-Salazar C, Demers JE, Clement DL, Rane KK, Crouch JA (2016) Sarcococca blight: Use of whole-genome sequencing for fungal plant disease diagnosis. Plant Disease 100: 1093-1100. https://doi.org/10.1094/PDIS-10-15-1159-RE

De Marco P, Nóbrega CC (2018) Evaluating collinearity effects on species distribution models: An approach based on virtual species simulation. PLoS ONE 13: e0202403. https://doi.org/10.1371/journal.pone.0202403

Marmion M, Parviainen M, Luoto M, Heikkinen RK, Thuiller W (2009) Evaluation of consensus methods in predictive species distribution modelling. Diversity and Distributions 15: 59-69. https://doi.org/10.1111/j.1472-4642.2008.00491.x

Matsiakh I (2016) Assessment of forest pests and diseases in native boxwood forests of Georgia: Final report. In: Forestry Department, Ukrainian National Forestry University (Lviv). Available at: https://www.enpi-

fleg.org/site/assets/files/1939/assessment_of_pests_and_diseases_in_georgian_forests_i_ma tsiakh_final_final.pdf. Available from: https://www.enpifleg.org/site/assets/files/1939/assessment_of_pests_and_diseases_in_georgian_forests_i_ma tsiakh_final_final.pdf.

Matsiakh I, Kramarets V, Mamadashvili G (2018) Box tree moth Cydalima perspectalis as a threat to the native populations of Buxus colchica in Republic of Georgia. Journal of the Entomological Research Society 20: 29-42.

Miller ME, Shishkoff N, Cubeta MA (2018) Thermal sensitivity of Calonectria henricotiae and Calonectria pseudonaviculata conidia and microsclerotia. Mycologia 110: 546-558. https://doi.org/10.1080/00275514.2018.1465778

Mirabolfathy M (2013) Outbreak of boxwood tree leaf drop in Guilan and Mazandaran forests. In: 1st Iranian Mycological Congress. University of Guilan, Rasht, Iran, 8.

Mirabolfathy M, Ahangaran Y, Lombard L, Crous PW (2013) Leaf blight of Buxus sempervirens 
in northern forests of Iran caused by Calonectria pseudonaviculata. Plant Disease 97: 1121. https://doi.org/10.1094/PDIS-03-13-0237-PDN

Mitchell R, Chitanava S, Dbar R, Kramarets V, Lehtijärvi A, Matchutadze I, Mamadashvili G, Matsiakh I, Nacambo S, Papazova-Anakieva I, Sathyapala S, Tuniyev B, Vétek G, Zukhbaia M, Kenis M (2018) Identifying the ecological and societal consequences of a decline in Buxus forests in Europe and the Caucasus. Biological Invasions 20: 3605-3620. https://doi.org/10.1007/s10530-018-1799-8

Nahrung HF, Carnegie AJ (2020) Non-native forest insects and pathogens in Australia: establishment, spread, and impact. Frontiers in Forests and Global Change 3: 1-12. https://doi.org/10.3389/ffgc.2020.00037

Owens HL, Campbell LP, Dornak LL, Saupe EE, Barve N, Soberón J, Ingenloff K, Lira-Noriega A, Hensz CM, Myers CE, Peterson AT (2013) Constraints on interpretation of ecological niche models by limited environmental ranges on calibration areas. Ecological Modelling 263: 10-18. https://doi.org/10.1016/j.ecolmodel.2013.04.011

Paini DR, Sheppard AW, Cook DC, Barro PJ De, Worner SP, Thomas MB (2016) Global threat to agriculture from invasive species. Proceedings of the National Academy of Sciences 113: 7575-7579. https://doi.org/10.1073/pnas.1602205113

\section{Palmer CL, Shishkoff N (2014) Boxwood blight: a new scourge, a new paradigm for} collaborative research. Outlooks on Pest Management 25: 230-236. https://doi.org/10.1564/v25_jun_10

Panahi P, Jamzad Z, Jalili A, Sagheb Talebi K, Pourhashemi M (2021) The role of the National Botanical Garden of Iran in ex situ conservation of Buxus hyrcana Pojark.; An endangered species. Urban Forestry \& Urban Greening 57: 126951. https://doi.org/10.1016/j.ufug.2020.126951

Patarkalashvili T (2017) Forest biodiversity of Georgia and endangered plant species. Annals of Agrarian Science 15: 349-351. https://doi.org/10.1016/j.aasci.2017.06.002

Peterson AT, Papeş M, Soberón J (2015) Mechanistic and correlative models of ecological niches. European Journal of Ecology 1: 28-38. https://doi.org/10.1515/eje-2015-0014 Petitpierre B, Broennimann O, Kueffer C, Daehler C, Guisan A (2017) Selecting predictors to maximize the transferability of species distribution models: lessons from cross-continental plant invasions. Global Ecology and Biogeography 26: 275-287. 
1138

1139

1140

1141

1142

1143

1144

1145

1146

1147

1148

1149

1150

1151

1152

1153

1154

1155

1156

1157

1158

1159

1160

1161

1162

1163

1164

1165

1166

1167

1168

https://doi.org/10.1111/geb.12530

Pfender WF, Gent DH, Mahaffee WF (2012) Sensitivity of disease management decision aids to temperature input errors associated with sampling interval and out-of-canopy sensor placement. Plant Disease 96: 726-736. https://doi.org/10.1094/PDIS-03-11-0262

Phillips SJ, Anderson RP, Schapire RE (2006) Maximum entropy modeling of species geographic distributions. Ecological Modelling 190: 231-259.

https://doi.org/10.1016/j.ecolmodel.2005.03.026

Phillips SJ, Anderson RP, Dudík M, Schapire RE, Blair ME (2017) Opening the black box: an open-source release of Maxent. Ecography 40: 887-893. https://doi.org/10.1111/ecog.03049

Pili AN, Tingley R, Sy EY, Diesmos MLL, Diesmos AC (2020) Niche shifts and environmental non-equilibrium undermine the usefulness of ecological niche models for invasion risk assessments. Scientific Reports 10: 1-18. https://doi.org/10.1038/s41598-020-64568-2

Pintos Varela C, Penalta BG, Vázquez JPM, Casal OA (2009) First report of Cylindrocladium buxicola on Buxus sempervirens in Spain. Plant Disease 93: 670-670. https://doi.org/https://doi.org/10.1094/PDIS-93-6-0670B

Prasad AM, Iverson LR, Liaw A (2006) Newer classification and regression tree techniques: bagging and random forests for ecological prediction. Ecosystems 9: 181-199. https://doi.org/10.1007/s10021-005-0054-1

R Development Core Team (2021) R: a language and environment for statistical computing. R Foundation for Statistical Computing, Vienna, Austria. http://www.R- project.org.

Rezaee S, Kia-Daliri H, Sharifi K, Ahangaran Y, Hajmansoor S (2013) Boxwood blight caused by Cylindrocladium buxicola in Tonekabon forest. Applied Entomology and Phytopathology 80: 197-198.

Ricciardi A, Blackburn TM, Carlton JT, Dick JTA, Hulme PE, Iacarella JC, Jeschke JM, Liebhold AM, Lockwood JL, MacIsaac HJ, Pyšek P, Richardson DM, Ruiz GM, Simberloff D, Sutherland WJ, Wardle DA, Aldridge DC (2017) Invasion science: a horizon scan of emerging challenges and opportunities. Trends in Ecology and Evolution 32: 464-474. https://doi.org/10.1016/j.tree.2017.03.007

Richardson PA, Daughtrey M, Hong C (2020) Indications of susceptibility to Calonectria pseudonaviculata in some common groundcovers and boxwood companion plants. Plant Disease 104: 1127-1132. https://doi.org/10.1094/PDIS-08-19-1582-RE 
1169 Ryan C, Williams-Woodward J, Zhang DL (2018) Susceptibility of Sarcococca taxa to boxwood 1170 blight by Calonectria pseudonaviculata. In: Proceedings of southern nursery association

1172 Safránková I, Kmoch M, Holková L (2012) First report of Cylindrocladium buxicola on box in

1173 Czech Republic. New Disease Reports 25: 5. https://doi.org/10.2307/3761865

1174 Salvesen PH, Kanz B (2009) Boxwood cultivars in old gardens in Norway. In: Morel J-P,

1175 Mercuri AM (Eds), Plants and Culture: Seeds of the Cultural Heritage of Europe. Edipuglia, 1176 Puglia, Italy, 247-262. Available from: http://www.plants-culture.unimore.it/book.htm.

1177 Santini A, Ghelardini L, De Pace C, Desprez-Loustau ML, Capretti P, Chandelier A, Cech T,

1178 Chira D, Diamandis S, Gaitniekis T, Hantula J, Holdenrieder O, Jankovsky L, Jung T, Jurc

1179 D, Kirisits T, Kunca A, Lygis V, Malecka M, Marcais B, Schmitz S, Schumacher J,

1180 Solheim H, Solla A, Szabò I, Tsopelas P, Vannini A, Vettraino AM, Webber J, Woodward

1181 S, Stenlid J (2013) Biogeographical patterns and determinants of invasion by forest pathogens in Europe. New Phytologist 197: 238-250. https://doi.org/10.1111/j.14698137.2012.04364.x

Saracchi M, Rocchi F, Pizzatti C, Cortesi P (2008) Box blight, a new disease of Buxus in Italy caused by Cylindrocladium buxicola. Journal of Plant Pathology 90: 581-584. https://doi.org/10.4454/jpp.v90i3.703

Saurat C, Fourrier C, Ioos R (2012) First report of blight disease on Buxus caused by Cylindrocladium buxicola in France. Plant Disease 96: 1069-1069. https://doi.org/https://doi.org/10.1094/PDIS-03-12-0242-PDN

Schatz GE, Lowry PPI (2002) A synoptic revision of the genus Buxus L. (Buxaceae) in

Senay SD, Worner SP, Ikeda T (2013) Novel three-step pseudo-absence selection technique for Madagascar and the Comoro Islands. Adansonia 24: 179-196. improved species distribution modelling. PLoS ONE 8: e71218. https://doi.org/10.1371/journal.pone.0071218

Shabani F, Kumar L, Ahmadi M (2016) A comparison of absolute performance of different correlative and mechanistic species distribution models in an independent area. Ecology and Evolution 6: 5973-5986. https://doi.org/10.1002/ece3.2332

Shishkoff N, Camp MJ (2016) The effect of different temperatures and moisture levels on survival of Calonectria pseudonaviculata in boxwood leaves and twigs and as 
1200

1201

1202

1203

1204

1205

1206

1207

1208

1209

1210

1211

1212

1213

1214

1215

1216

1217

1218

1219

1220

1221

1222

1223

1224

1225

1226

1227

1228

1229

1230

microsclerotia produced in culture. Plant Disease 100: 2018-2024.

https://doi.org/10.1094/PDIS-09-15-1098-RE

Shishkoff N, Daughtrey M, Aker S, Olsen RT, Disease UF, Science W, Daughtrey M, Island L (2015) Evaluating boxwood susceptibility to Calonectria pseudonaviculata using cuttings from the national boxwood collection. Plant Health Progress 16: 11-15. https://doi.org/10.1094/php-rs-14-0033

Şimşek SA, Katırcıoğlu YZ, Çakar D, Rigling D, Maden S (2019) Impact of fungal diseases on common box (Buxus sempervirens L.) vegetation in Turkey. European Journal of Plant Pathology 153: 1203-1220. https://doi.org/10.1007/s10658-018-01636-4

Van der Straten MJ, Muus TST (2010) The box tree pyralid, Glyphodes perspectalis (Lepidoptera: Crambidae), an invasive alien moth ruining box trees. Proceedings of the Netherlands Entomological Society Meeting 21: 107-111. Available from: http://www.nev.nl/pages/publicaties/proceedings/nummers/21/1-136.pdf\#page=107.

Sutherst RW (2014) Pest species distribution modelling: origins and lessons from history. Biological Invasions 16: 239-256. https://doi.org/10.1007/s10530-013-0523-y

Sutherst RW, Maywald GF (1985) A computerised system for matching climates in ecology. Agriculture, Ecosystems and Environment 13: 281-299. https://doi.org/10.1016/01678809(85)90016-7

Taylor S, Kumar L (2012) Sensitivity analysis of CLIMEX parameters in modelling potential distribution of Lantana camara L. PLoS ONE 7: e40969. https://doi.org/10.1371/journal.pone.0040969

Thakur MP, van der Putten WH, Cobben MMP, van Kleunen M, Geisen S (2019) Microbial invasions in terrestrial ecosystems. Nature Reviews Microbiology 17: 621-631. https://doi.org/10.1038/s41579-019-0236-z

Thuiller W (2004) Patterns and uncertainties of species' range shifts under climate change. Global Change Biology 10: 2020-2027. https://doi.org/10.1111/j.1365-2486.2004.00859.x United States Department of Agriculture (1976) Growing boxwoods. U.S. Department of Agriculture, Washington, D.C.

USDA National Agricultural Statistics Service (2020) Census of Horticultural Specialties. Available at: https://www.nass.usda.gov/Publications/AgCensus/2017/Online_Resources/Census_of_Hor 
1231 ticulture_Specialties/.

1232 USGCRP (2018) Impacts, Risks, and Adaptation in the United States: Fourth National Climate 1233 Assessment, Volume II. Reidmiller DR, Avery CW, Easterling DR, Kunkel KE, Lewis

1234 KLM, Maycock TK, Stewar BC (Eds). U.S. Global Change Research Program,

1235 Washington, DC, USA, 1515 pp. https://doi.org/10.7930/NCA4.2018

1236 Vale CG, Tarroso P, Brito JC (2014) Predicting species distribution at range margins: testing the

1237 effects of study area extent, resolution and threshold selection in the Sahara-Sahel transition 1238 zone. Diversity and Distributions 20: 20-33. https://doi.org/10.1111/ddi.12115

1239 Veloz SD (2009) Spatially autocorrelated sampling falsely inflates measures of accuracy for 1240 presence-only niche models. Journal of Biogeography 36: 2290-2299.

$1241 \quad$ https://doi.org/10.1111/j.1365-2699.2009.02174.x

1242 Watling JI, Brandt LA, Bucklin DN, Fujisaki I, Mazzotti FJ, Romañach SS, Speroterra C (2015)

1243 Performance metrics and variance partitioning reveal sources of uncertainty in species

1244 distribution models. Ecological Modelling 309-310: 48-59.

$1245 \quad$ https://doi.org/10.1016/j.ecolmodel.2015.03.017

1246 Yang X, Hong C (2018) Microsclerotial enumeration, size, and survival of Calonectria

1247 pseudonaviculata. Plant Disease 102: 983-990. https://doi.org/10.1094/PDIS-08-17-1249-

$1248 \quad \mathrm{RE}$

1249 Zurell D, Elith J, Schröder B (2012) Predicting to new environments: Tools for visualizing

1250 model behaviour and impacts on mapped distributions. Diversity and Distributions 18: 628-

1251 634. https://doi.org/10.1111/j.1472-4642.2012.00887.x

1252 
Tables and Figures

1254

1255 Table 1. CLIMEX parameter values for Calonectria pseudonaviculata.

1256

1257 Table 2. Summary of the principal component analysis of 27 bioclimatic variables used for 1258 correlative models. Principal component (PC) axes were selected until the cumulative 1259 explanation proportion reached $95 \%$ or more of the total variation of the original matrix.

1260 Loadings of PCs for each variable are presented, as well as PC's eigenvalues, the proportion of 1261 explained variance of each PC, and accumulated proportion of explained variance. The largest 1262 loadings (positive or negative) for each component $(>0.30)$ are indicated with bold font.

Table 3. Mean values of evaluation statistics for individual correlative models and the ensemble 1265 model.

Table 4. The percent contribution of each principal component (PC) variable to correlative 1268 models produced by six algorithms. The climatic relevance of each variable [based on which 1269 bioclimatic variables had the largest loadings (positive or negative, Table 2)] and the average and range of contributions across all algorithms is indicated.

1272 Figure 1. Maps of climatic suitability and potential distribution for Calonectria

1273 pseudonaviculata in Europe and western Asia. Climatic suitability is estimated as the ecoclimatic 1274 index in the CLIMEX model $\mathbf{A}$ with and $\mathbf{B}$ without irrigation, and as $\mathbf{C}$ the probability of 1275 occurrence in the ensemble correlative model. Areas of overlap in the potential distribution 1276 (purple shading) according to both CLIMEX models (ecoclimatic index $=10-100$ ) and the 1277 ensemble correlative model (presence predictions) are shown in comparison to areas that were 1278 included in the potential distribution by only one model [red shading = CLIMEX model (no 1279 irrigation); orange shading = CLIMEX model (including irrigation); blue shading = ensemble correlative model]. Black circles represent the approximate locations of occurrence records.

1282 Figure 2. Population growth and climate stress accumulation for Calonectria pseudonaviculata 1283 in Europe and western Asia. Population growth in CLIMEX is measured as the A annual growth 
1284 index (annual growth index, range $=0-100$ ). Climate stress indices (range $=0-999$ ) include $\mathbf{B}$

1285 cold stress, $\mathbf{C}$ heat stress, and $\mathbf{D}$ dry stress. Results are for the CLIMEX model which did not 1286 include irrigation.

1288 Figure 3. Maps of climatic suitability and the potential distribution for Calonectria

1289 pseudonaviculata in North America. Climatic suitability is estimated as the ecoclimatic index in

1290 the CLIMEX model $\mathbf{A}$ with and $\mathbf{B}$ without irrigation, and as $\mathbf{C}$ the probability of occurrence in 1291 the ensemble correlative model. Areas of overlap in the potential distribution (purple shading) 1292 according to both CLIMEX models (ecoclimatic index $=10-100)$ and the ensemble correlative 1293 model (presence predictions) are shown in comparison to areas that were included in the 1294 potential distribution by only one model [red shading = CLIMEX model (no irrigation); orange 1295 shading = CLIMEX model (including irrigation); blue shading = ensemble correlative model]. 1296 Black circles represent the approximate locations of occurrence records.

Figure 4. Population growth and climate stress accumulation for Calonectria pseudonaviculata 1299 in North America. Population growth in CLIMEX is measured as the A annual growth index 1300 (annual growth index, range $=0-100$ ). Climate stress indices (range $=0-999$ ) include $\mathbf{B}$ cold 1301 stress, $\mathbf{C}$ heat stress, and $\mathbf{D}$ dry stress.

1303 Figure 5. Climatic suitability for Calonectria pseudonaviculata globally. Climatic suitability is 1304 estimated as A the ecoclimatic index in the CLIMEX model (includes irrigation), and as $\mathbf{B}$ the 1305 probability of occurrence in the ensemble correlative model. Areas where the ecoclimatic index 1306 is zero and the probability of occurrence is less than 0.1 are shown in gray.

1308 Figure 6. Map of the global potential distribution for Calonectria pseudonaviculata. Areas of 1309 overlap in the potential distribution (purple shading) according to both CLIMEX models 1310 (ecoclimatic index $=10-100)$ and the ensemble correlative model (presence predictions) are 1311 shown in comparison to areas that were included in the potential distribution by only one model 1312 (red shading = CLIMEX model; orange shading = CLIMEX model that included irrigation; blue 1313 shading $=$ ensemble correlative model). 
1315 Figure 7. Mobility-oriented parity (MOP) assessment outputs for projections of the ensemble 1316 correlative model for Calonectria pseudonaviculata. Areas with MOP metric values close to 1

1317 have highly comparable climatic conditions to the those in the model calibration area. Areas with

1318 values approaching 0 indicate higher extrapolation because one or more climatic variables have

1319 values outside the range of variable(s) in the calibration area.

1321 Figure 8. Climate comparisons for sites which are expected to differ in favorability for boxwood 1322 blight infections. Line plots depict monthly temperature (solid lines) and precipitation (dashed 1323 lines) across eight sites in Europe (orange lines) and the United States (blue lines). Sites with a 1324 Mediterranean climate (e.g., Cannes, France; Naples, Italy; Seattle, Washington; and Portland, 1325 Oregon) are less conducive for infections than sites which have higher humidity, few gaps in 1326 precipitation, and ideal temperatures for growth throughout the year, such as those in 1327 temperate/coastal climates in western Europe (e.g., Brussels, Belgium and Bordeaux, France) 1328 and warm and humid climates in the mid-Atlantic and southeastern regions of the United States 1329 (e.g., Virginia Beach, Virginia and Atlanta, Georgia). Data source: 1981-2010 climate normals, 1330 World Meteorological Organization (https://climatedata-catalogue.wmo.int; accessed 24 Sep 1331 2021). 
1333 Table 1. CLIMEX parameter values for Calonectria pseudonaviculata.

1334

\begin{tabular}{llr}
\hline Parameter & Description & \multicolumn{1}{r}{ Value } \\
\hline Parameter & & \\
SM0 & Limiting low moisture & 0.2 \\
SM1 & Lower optimal moisture & 0.7 \\
SM2 & Upper optimal moisture & 1.7 \\
SM3 & Limiting high moisture & 3.0 \\
Temperature & & \\
DV0 & Limiting low temperature $\left({ }^{\circ} \mathrm{C}\right)$ & 8 \\
DV1 & Lower optimal temperature $\left({ }^{\circ} \mathrm{C}\right)$ & 21 \\
DV2 & Upper optimal temperature $\left({ }^{\circ} \mathrm{C}\right)$ & 25 \\
DV3 & Limiting high temperature $\left({ }^{\circ} \mathrm{C}\right)$ & 29 \\
Cold stress & & \\
TTCS & Cold stress temperature threshold $\left({ }^{\circ} \mathrm{C}\right)$ & -10 \\
TCCS & Cold stress temperature rate $\left(\right.$ week $\left.^{-1}\right)$ & -0.005 \\
Heat stress & & \\
TTHS & Heat stress temperature threshold $\left({ }^{\circ} \mathrm{C}\right)$ & 32 \\
THHS & Heat stress temperature rate $\left(\right.$ week $\left.^{-1}\right)$ & 0.01 \\
Dry stress & & \\
SMDS & Dry stress threshold & 0.2 \\
HDS & Dry stress rate $\left(\right.$ week $\left.^{-1}\right)$ & -0.001 \\
Wet stress & & \\
SMWS & Wet stress threshold \\
HWS & Wet stress rate $\left(\right.$ week $\left.^{-1}\right)$ & 3.0 \\
\hline
\end{tabular}


1335 Table 2. Summary of the principal component analysis of 27 bioclimatic variables used for

1336 correlative models. Principal component (PC) axes were selected until the cumulative

1337 explanation proportion reached $95 \%$ or more of the total variation of the original matrix.

1338 Loadings of PCs for each variable are presented, as well as PC's eigenvalues, the proportion of

1339 explained variance of each PC, and accumulated proportion of explained variance. The largest

1340 loadings (positive or negative) for each component $(>0.30)$ are indicated with bold font.

1341

\begin{tabular}{|c|c|c|c|c|c|c|}
\hline Variables and proportion of variance & $\mathrm{PC} 1$ & $\mathrm{PC} 2$ & PC3 & PC4 & PC5 & PC6 \\
\hline \multicolumn{7}{|l|}{ Variable } \\
\hline Annual mean temperature (bio1) & 0.033 & 0.212 & 0.298 & -0.001 & -0.001 & -0.014 \\
\hline Mean diurnal temperature range (bio2) & 0.083 & -0.164 & 0.261 & -0.226 & -0.369 & -0.199 \\
\hline Isothermality (bio3) & 0.012 & 0.235 & 0.082 & -0.192 & -0.271 & -0.066 \\
\hline Temperature seasonality (bio4) & 0.06 & -0.484 & 0.06 & 0.006 & 0.039 & 0.023 \\
\hline Max temperature of warmest week (bio5) & 0.12 & -0.013 & 0.404 & -0.023 & -0.023 & -0.068 \\
\hline Min temperature of coldest week (bio6) & 0.023 & 0.365 & 0.151 & 0.027 & 0.035 & -0.003 \\
\hline Temperature annual range (bio7) & 0.095 & -0.562 & 0.208 & -0.065 & -0.077 & -0.069 \\
\hline Mean temperature of wettest quarter (bio8) & -0.317 & -0.024 & 0.566 & 0.07 & 0.118 & 0.361 \\
\hline Mean temperature of driest quarter (bio9) & 0.204 & 0.246 & 0.098 & -0.029 & -0.04 & -0.184 \\
\hline Mean temperature of warmest quarter (bio10) & 0.082 & 0.051 & 0.4 & 0.006 & 0.019 & -0.017 \\
\hline Mean temperature of coldest quarter (bio11) & 0.013 & 0.321 & 0.187 & -0.004 & -0.019 & -0.017 \\
\hline Annual precipitation (bio12) & -0.075 & -0.002 & 0.019 & -0.3 & 0.054 & -0.179 \\
\hline Precipitation of wettest week (bio13) & -0.059 & -0.027 & 0.016 & -0.484 & 0.073 & 0.066 \\
\hline Precipitation of driest week (bio14) & -0.142 & 0.034 & -0.009 & -0.054 & -0.041 & -0.415 \\
\hline Precipitation seasonality (bio15) & 0.001 & 0.095 & -0.169 & -0.389 & -0.258 & 0.574 \\
\hline Precipitation of wettest quarter (bio16) & -0.056 & -0.025 & 0.012 & -0.464 & 0.077 & 0.035 \\
\hline Precipitation of driest quarter (bio17) & -0.132 & 0.028 & 0.003 & -0.075 & -0.028 & -0.405 \\
\hline Precipitation of warmest quarter (bio18) & -0.386 & -0.054 & 0.141 & -0.157 & -0.004 & -0.01 \\
\hline Precipitation of coldest quarter (bio19) & 0.174 & 0.033 & -0.08 & -0.373 & 0.091 & -0.216 \\
\hline Annual mean moisture index (bio28) & -0.138 & 0.012 & -0.011 & -0.041 & 0.27 & -0.041 \\
\hline Highest weekly moisture index (bio29) & 0.032 & -0.005 & 0.007 & -0.112 & 0.427 & 0.041 \\
\hline Lowest weekly moisture index (bio30) & -0.317 & 0.032 & -0.075 & 0.001 & 0.036 & -0.082 \\
\hline Moisture index seasonality (bio31) & 0.497 & 0.052 & 0.013 & -0.101 & 0.195 & 0.09 \\
\hline Mean moisture index of wettest quarter (bio32) & 0.026 & -0.005 & 0.008 & -0.093 & 0.426 & 0.024 \\
\hline Mean moisture index of driest quarter (bio33) & -0.31 & 0.03 & -0.061 & -0.004 & 0.055 & -0.08 \\
\hline Mean moisture index of warmest quarter (bio34) & -0.345 & 0.036 & -0.093 & -0.054 & 0.02 & 0.003 \\
\hline Mean moisture index of coldest quarter (bio35) & 0.051 & -0.003 & 0.072 & -0.036 & 0.44 & -0.077 \\
\hline \multicolumn{7}{|l|}{ Proportion of variance } \\
\hline Proportion explained by each PC (\%) & 52.2 & 27.3 & 6.4 & 4.1 & 3.2 & 2.6 \\
\hline Accumulated proportion explained by the PCs (\%) & 52.2 & 79.5 & 85.9 & 90 & 93.2 & 95.8 \\
\hline
\end{tabular}


1342 Table 3. Mean values of evaluation statistics for individual correlative models and the ensemble model.

1343

\begin{tabular}{lllllll}
\hline Algorithm & AUC & Kappa & TSS & Jaccard & Sørensen & $\mathrm{F}_{\mathrm{pb}}$ \\
\hline Boosted regression tree & 0.998 & 0.974 & 0.974 & 0.975 & 0.987 & 1.949 \\
Generalized additive models & 0.996 & 0.986 & 0.986 & 0.986 & 0.993 & 1.972 \\
Bayesian Gaussian process & 0.999 & 0.982 & 0.982 & 0.982 & 0.991 & 1.965 \\
Maxent & 0.998 & 0.974 & 0.974 & 0.975 & 0.987 & 1.949 \\
Random forests & 0.998 & 0.978 & 0.978 & 0.978 & 0.989 & 1.956 \\
Support vector machine & 1 & 0.992 & 0.992 & 0.992 & 0.996 & 1.984 \\
Ensemble & 1 & 0.996 & 0.996 & 0.996 & 0.998 & 1.992 \\
\hline
\end{tabular}

1344

1345 AUC, Area Under the ROC Curve; TSS, True Skill Statistics; Fpb, F-measure on presence-background 
1347 Table 4. The percent contribution of each principal component (PC) variable to correlative models produced by six algorithms. The 1348 climatic relevance of each variable [based on which bioclimatic variables had the largest loadings (positive or negative, Table 2)] and 1349 the average and range of contributions across all algorithms is indicated.

1350

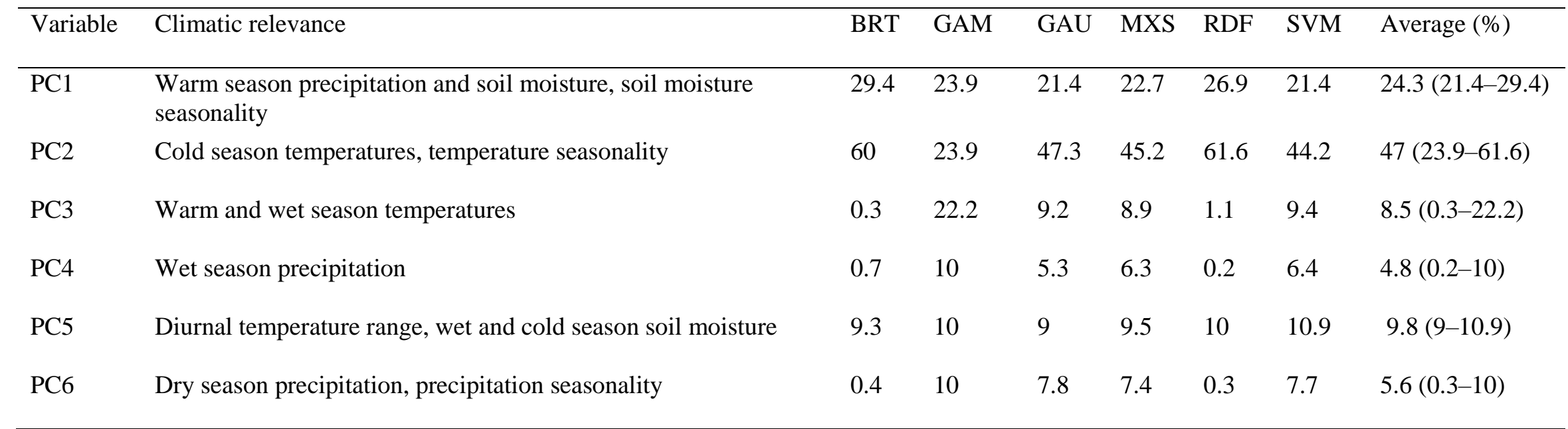

1352 BRT, boosted regression tree; GAM, generalized additive models; GAU, Gaussian process; MXS, Maxent "simple"; RDF, random 1353 forests; SVM, support vector machine. 
1354 Figure 1. Maps of climatic suitability and potential distribution for Calonectria

1355 pseudonaviculata in Europe and western Asia. Climatic suitability is estimated as the ecoclimatic

1356 index in the CLIMEX model $\mathbf{A}$ with and $\mathbf{B}$ without irrigation, and as $\mathbf{C}$ the probability of

1357 occurrence in the ensemble correlative model. Areas of overlap in the potential distribution

1358 (purple shading) according to both CLIMEX models (ecoclimatic index $=10-100$ ) and the

1359 ensemble correlative model (presence predictions) are shown in comparison to areas that were

1360 included in the potential distribution by only one model [red shading = CLIMEX model (no

1361 irrigation); orange shading = CLIMEX model (including irrigation); blue shading = ensemble

1362 correlative model]. Black circles represent the approximate locations of occurrence records.

1363

(A) CLIMEX model

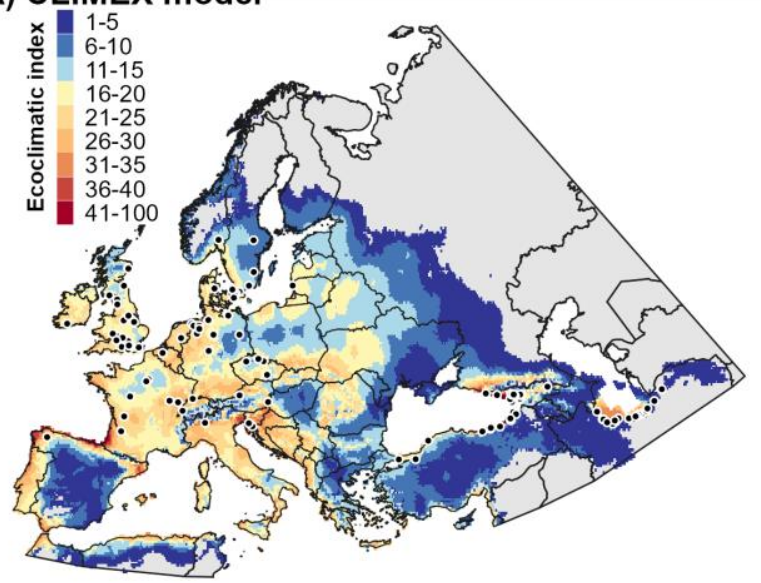

(C) Correlative model (ensemble)

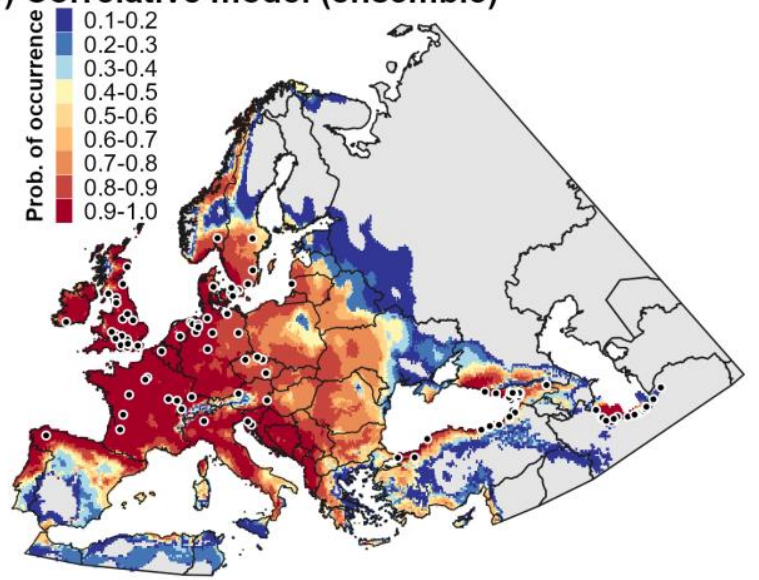

(B) CLIMEX model with irrigation

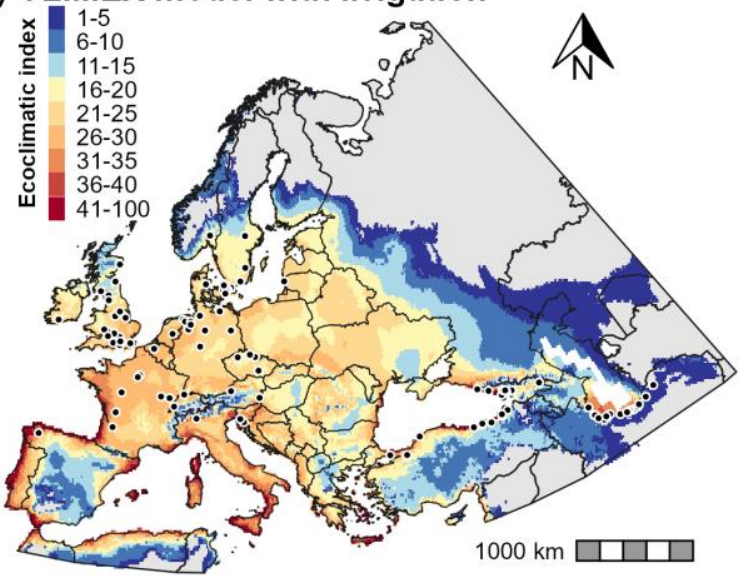

(D) Potential distribution

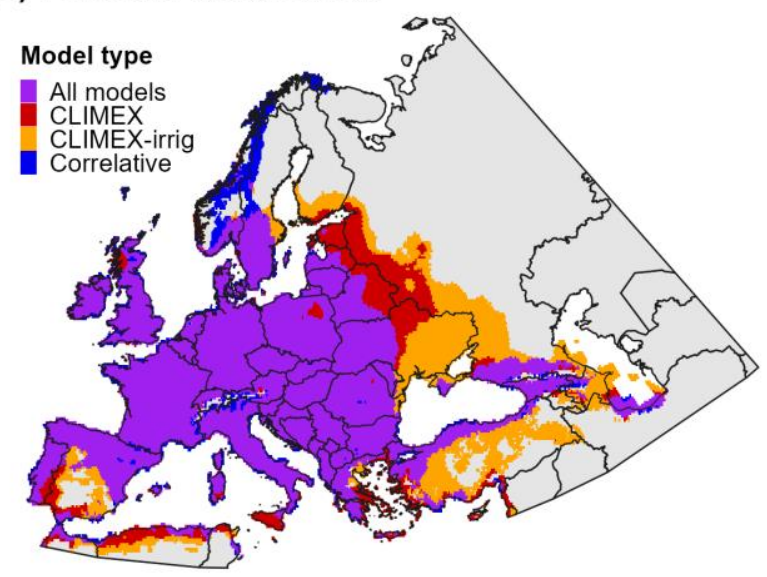


1366 Figure 2. Population growth and climate stress accumulation for Calonectria pseudonaviculata 1367 in Europe and western Asia. Population growth in CLIMEX is measured as the A annual growth 1368 index (annual growth index, range $=0-100$ ). Climate stress indices (range $=0-999$ ) include $\mathbf{B}$ 1369 cold stress, C heat stress, and D dry stress. Results are for the CLIMEX model which did not 1370 include irrigation.

1371

(A) Growth index

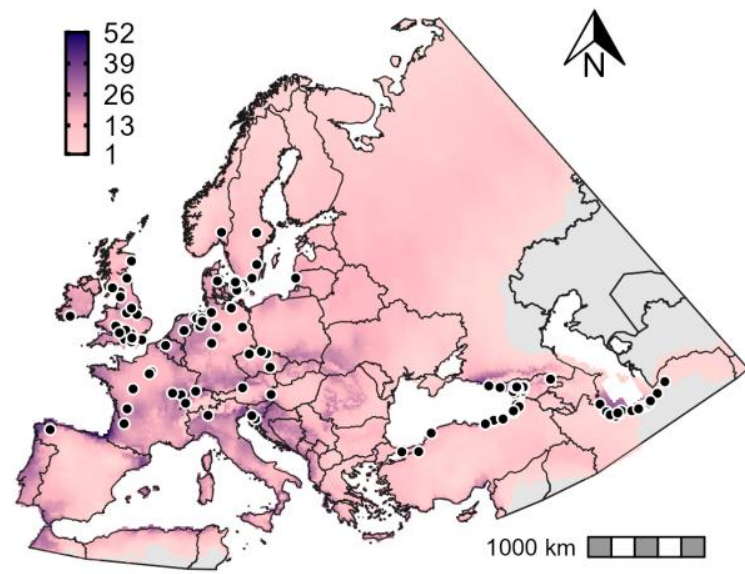

(C) Heat stress

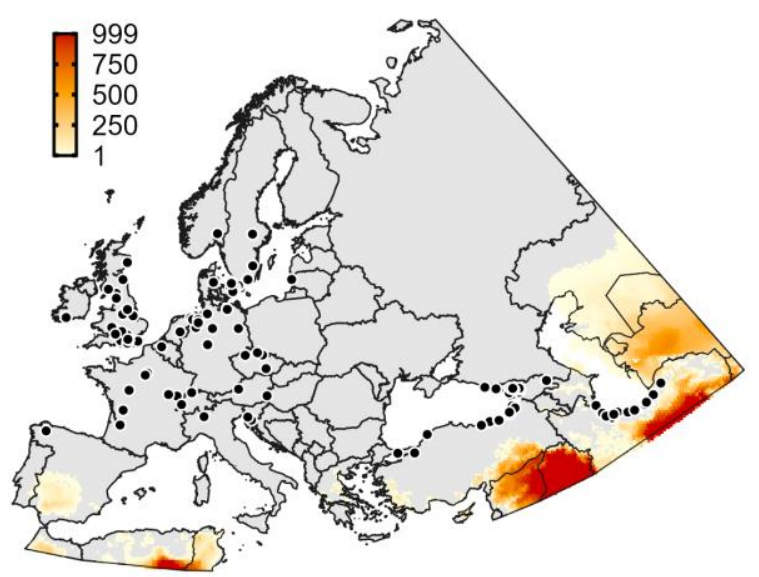

(B) Cold stress

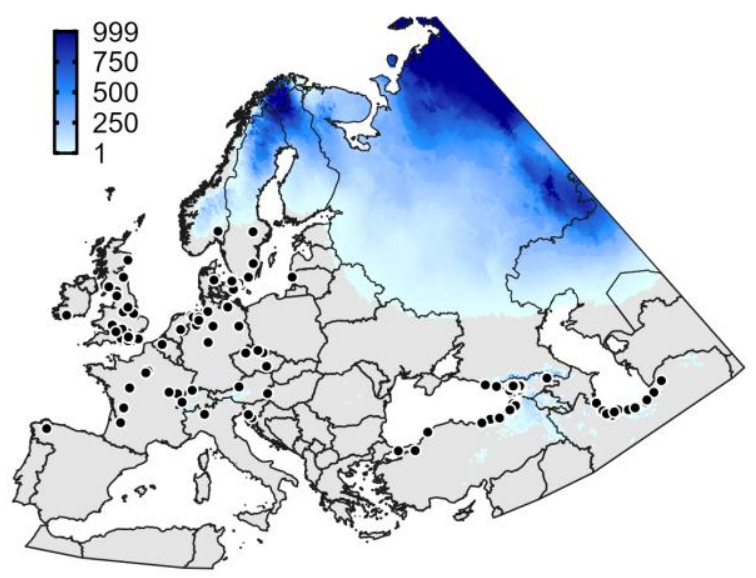

(D) Dry stress

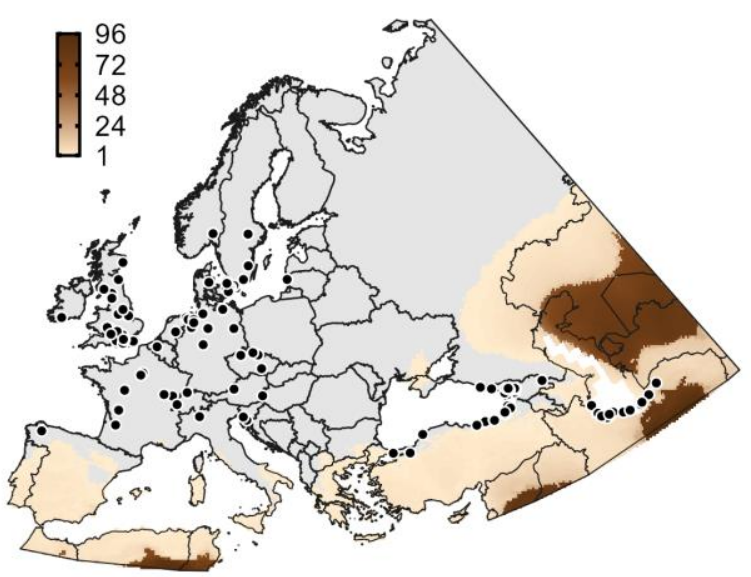


1374 Figure 3. Maps of climatic suitability and the potential distribution for Calonectria

1375 pseudonaviculata in North America. Climatic suitability is estimated as the ecoclimatic index in

1376 the CLIMEX model $\mathbf{A}$ with and $\mathbf{B}$ without irrigation, and as $\mathbf{C}$ the probability of occurrence in

1377 the ensemble correlative model. Areas of overlap in the potential distribution (purple shading)

1378 according to both CLIMEX models (ecoclimatic index $=10-100)$ and the ensemble correlative

1379 model (presence predictions) are shown in comparison to areas that were included in the

1380 potential distribution by only one model [red shading = CLIMEX model (no irrigation); orange

1381 shading = CLIMEX model (including irrigation); blue shading = ensemble correlative model].

1382 Black circles represent the approximate locations of occurrence records.

1383

(A) CLIMEX model

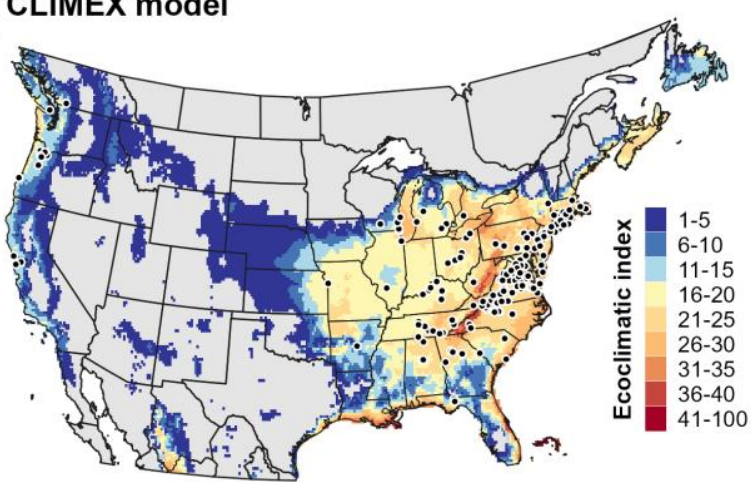

(C) Correlative model (ensemble)

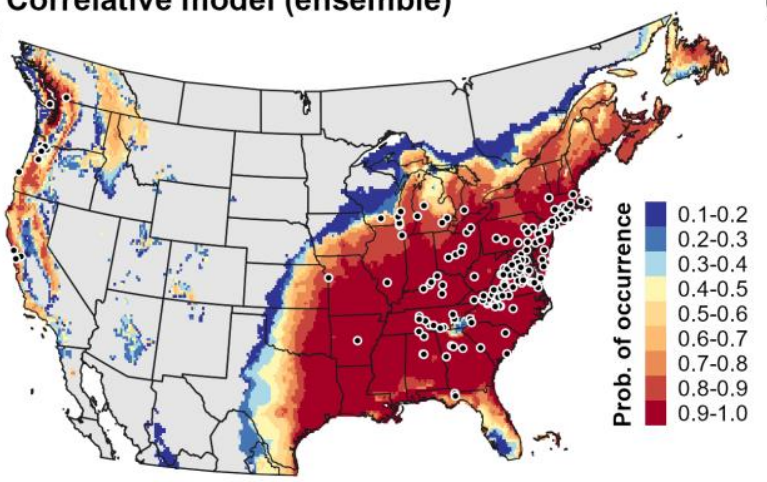

(B) CLIMEX model with irrigation

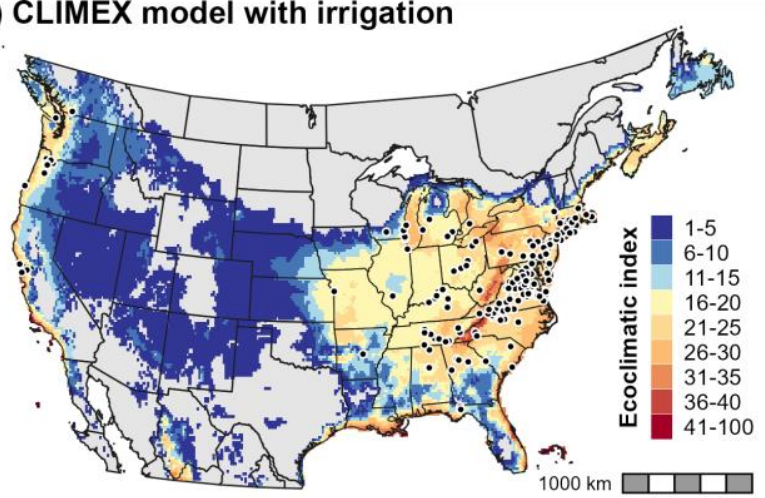

(D) Potential distribution

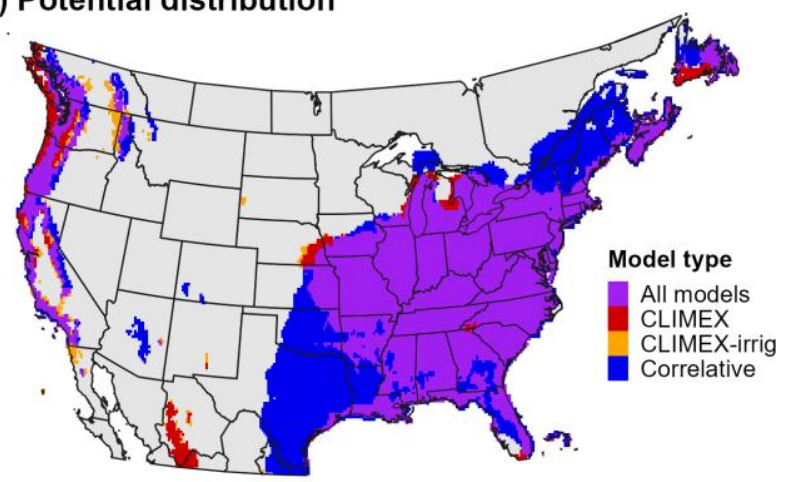


1386 Figure 4. Population growth and climate stress accumulation for Calonectria pseudonaviculata 1387 in North America. Population growth in CLIMEX is measured as the A annual growth index 1388 (annual growth index, range $=0-100$ ). Climate stress indices (range $=0-999$ ) include $\mathbf{B}$ cold 1389 stress, $\mathbf{C}$ heat stress, and $\mathbf{D}$ dry stress.

1390

(A) Growth index

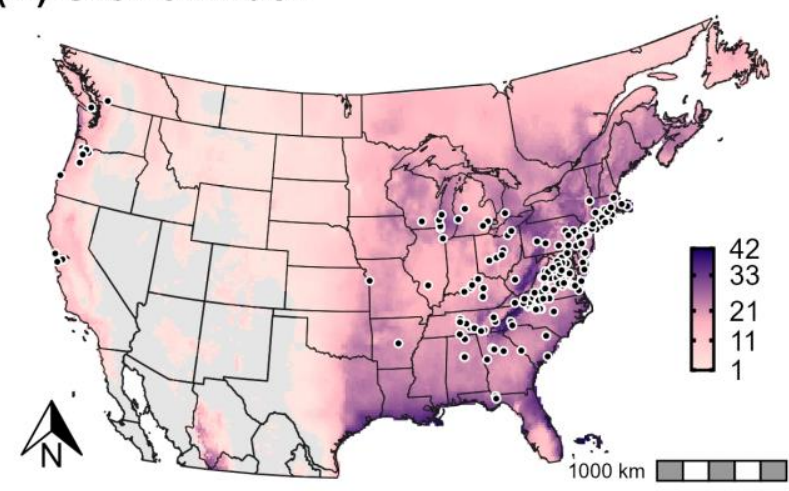

(C) Heat stress

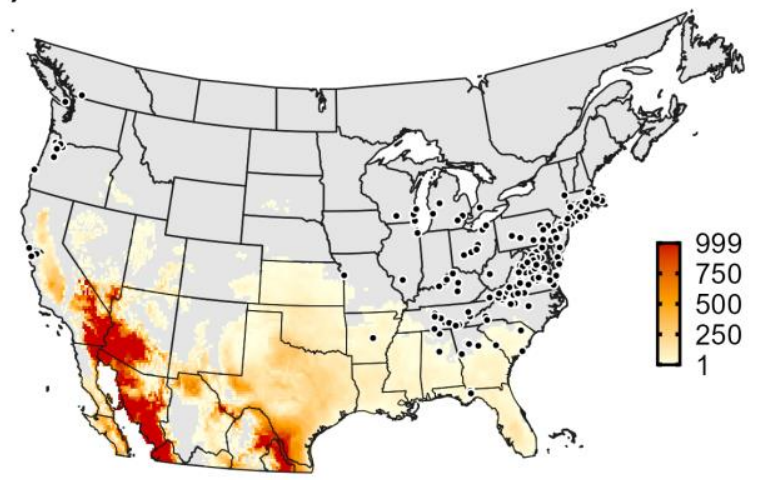

(B) Cold stress

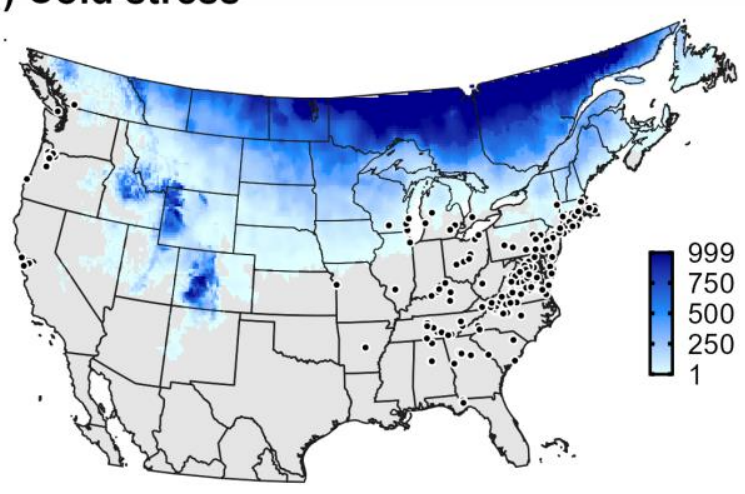

(D) Dry stress

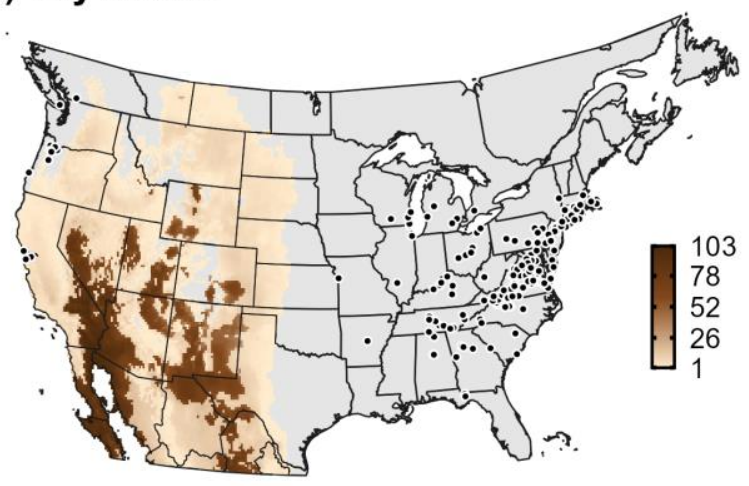


1393 Figure 5. Climatic suitability for Calonectria pseudonaviculata globally. Climatic suitability is 1394 estimated as A the ecoclimatic index in the CLIMEX model (includes irrigation), and as B the 1395 probability of occurrence in the ensemble correlative model. Areas where the ecoclimatic index 1396 is zero and the probability of occurrence is less than 0.1 are shown in gray.

\section{(A) CLIMEX}

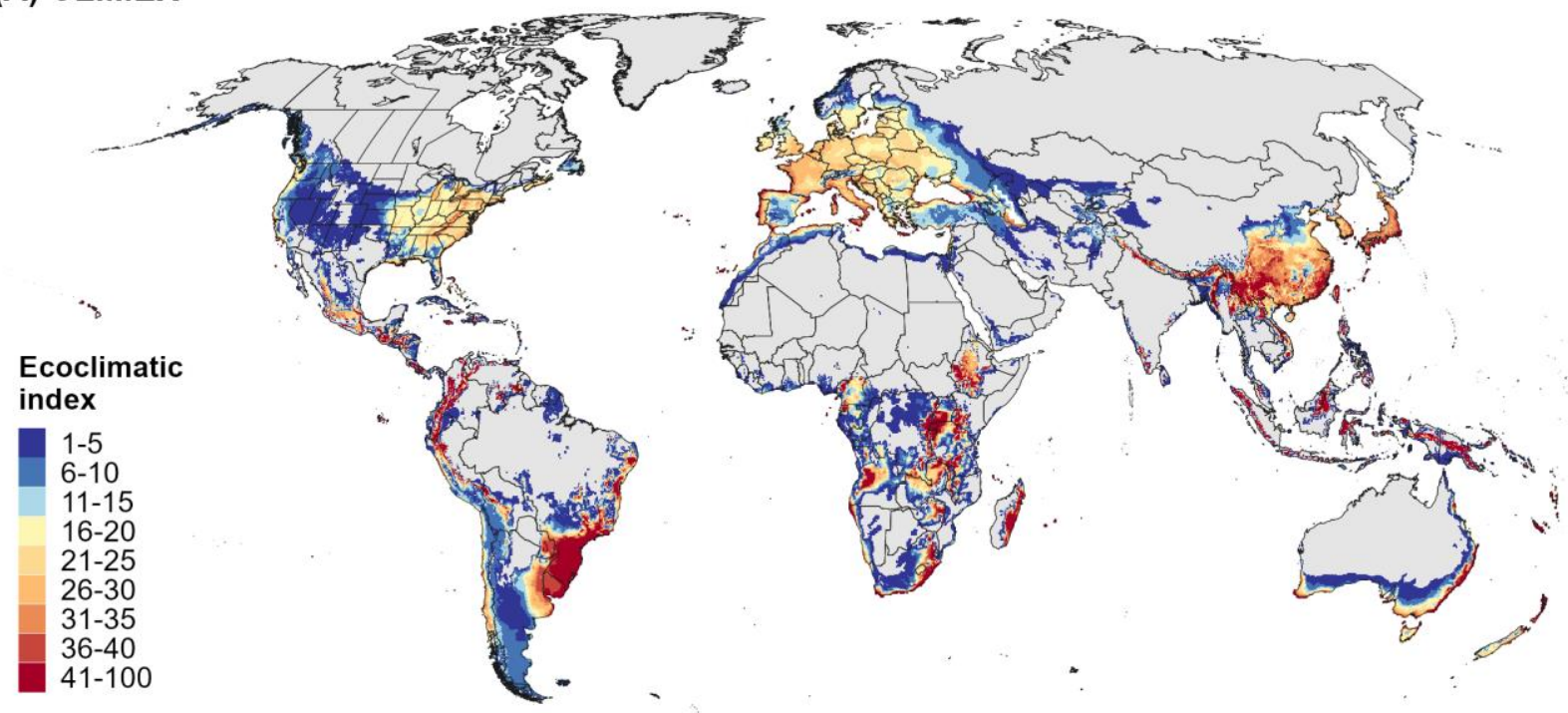

(B) Correlative (ensemble)

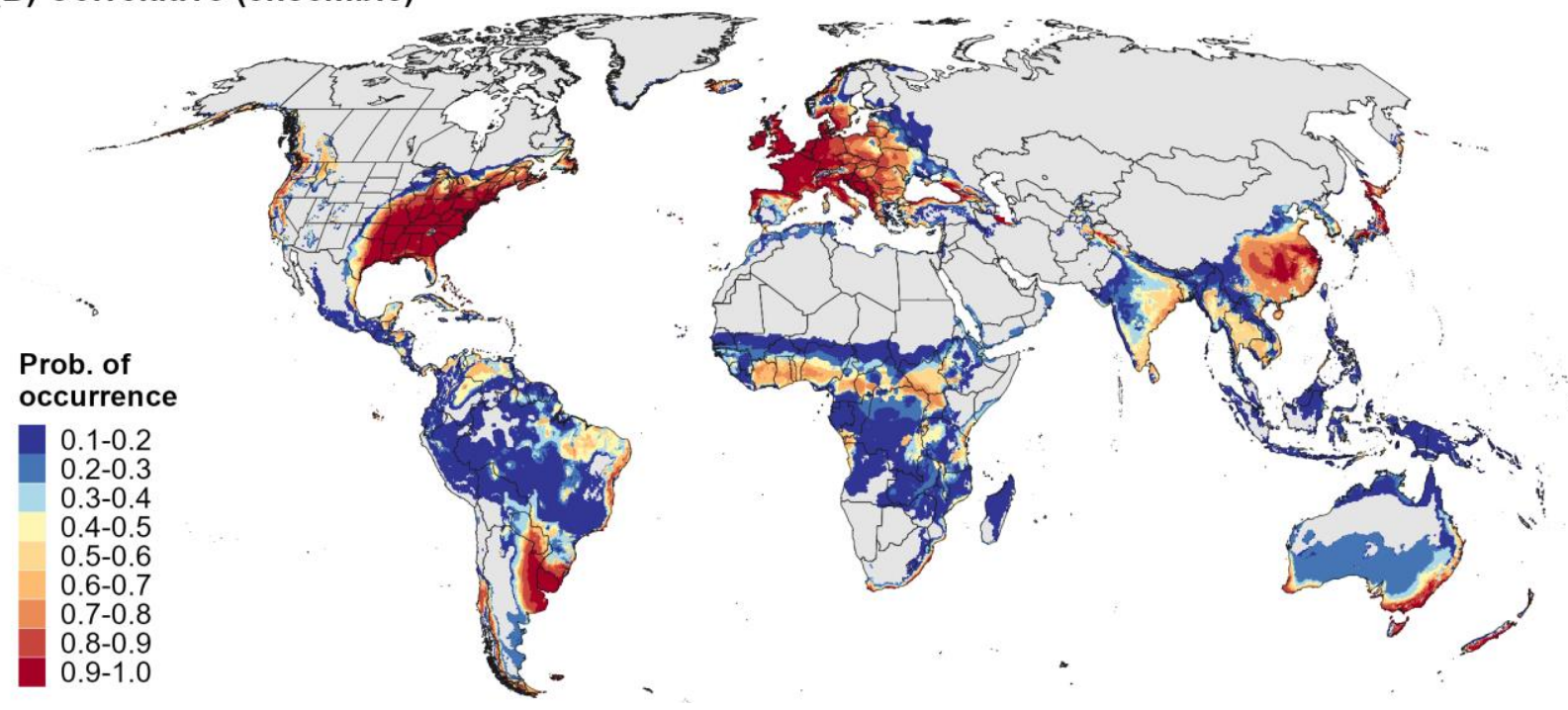


1399 Figure 6. Map of the global potential distribution for Calonectria pseudonaviculata. Areas of overlap in the potential distribution

1400 (purple shading) according to both CLIMEX models (ecoclimatic index $=10-100$ ) and the ensemble correlative model (presence 1401 predictions) are shown in comparison to areas that were included in the potential distribution by only one model (red shading $=$ 1402 CLIMEX model; orange shading = CLIMEX model that included irrigation; blue shading = ensemble correlative model).

1403

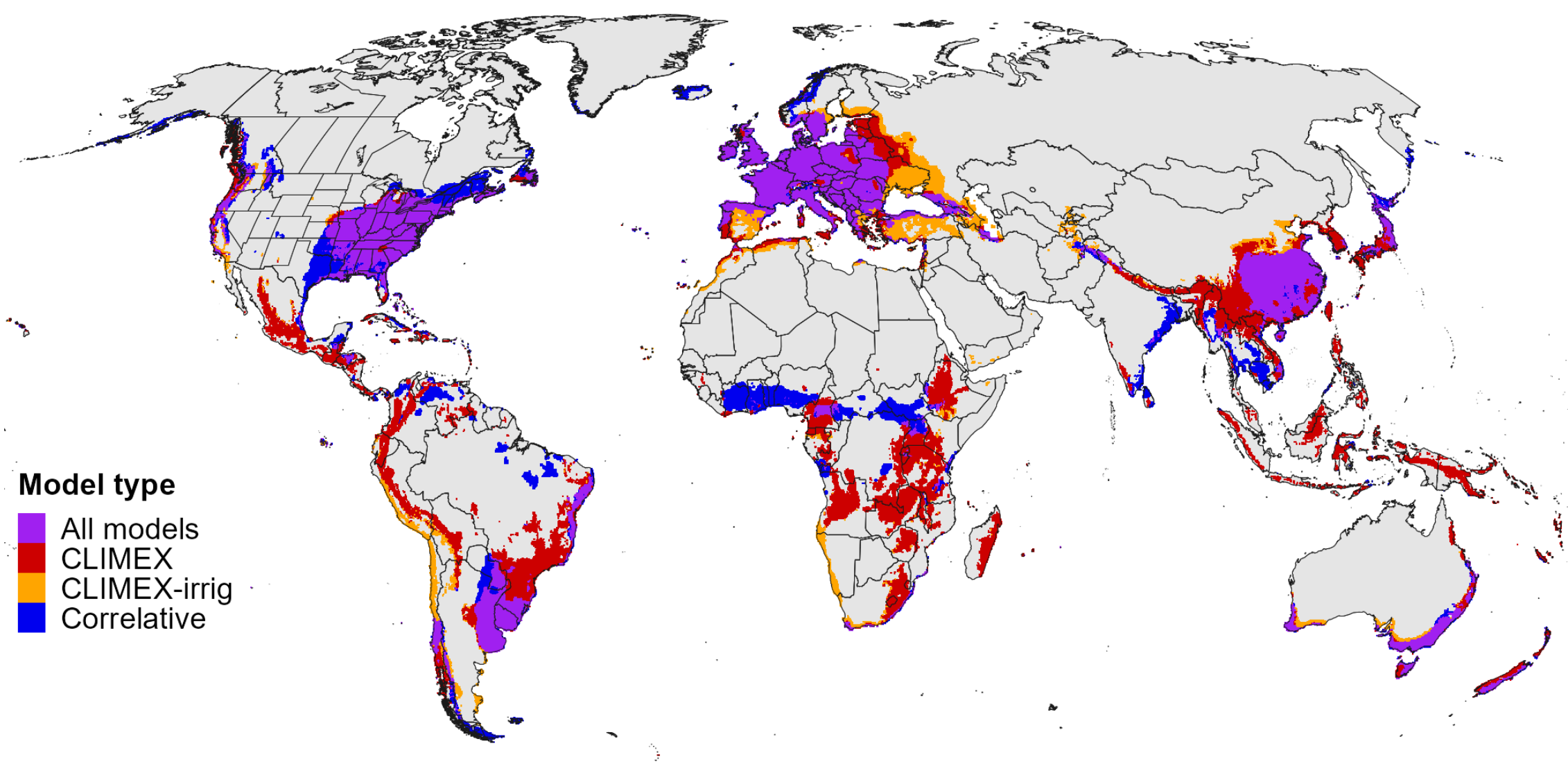


1405

1406

1407

1408

1409
Figure 7. Mobility-oriented parity (MOP) assessment outputs for projections of the ensemble correlative model for Calonectria pseudonaviculata. Areas with MOP metric values close to 1 have highly comparable climatic conditions to the those in the model calibration area. Areas with values approaching 0 indicate higher extrapolation because one or more climatic variables have values outside the range of variable(s) in the calibration area.

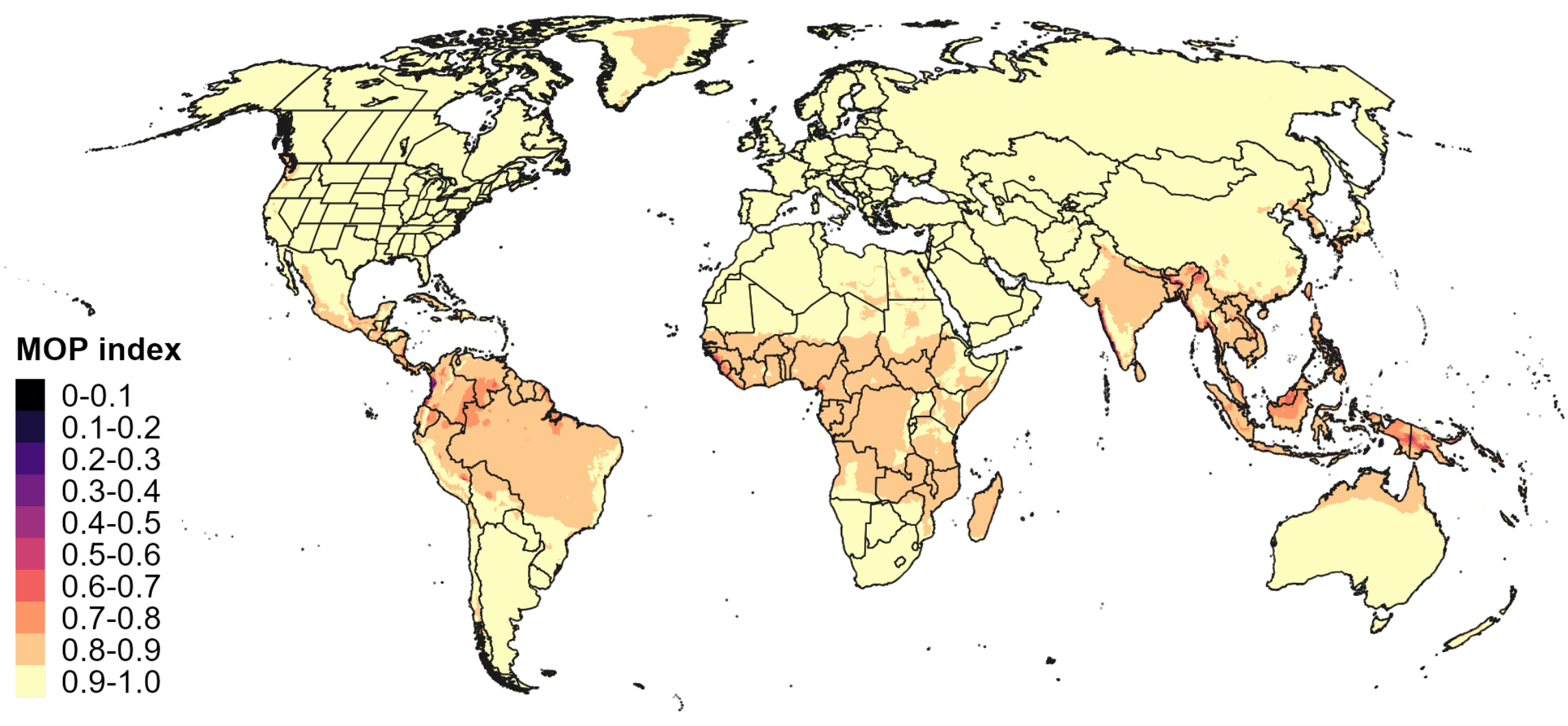


1411 Figure 8. Climate comparisons for sites which are expected to differ in favorability for boxwood 1412 blight infections. Line plots depict monthly temperature (solid lines) and precipitation (dashed 1413 lines) across eight sites in Europe (orange lines) and the United States (blue lines). Sites with a 1414 Mediterranean climate (e.g., Cannes, France; Naples, Italy; Seattle, Washington; and Portland, 1415 Oregon) are less conducive for infections than sites which have higher humidity, few gaps in 1416 precipitation, and ideal temperatures for growth throughout the year, such as those in 1417 temperate/coastal climates in western Europe (e.g., Brussels, Belgium and Bordeaux, France) 1418 and warm and humid climates in the mid-Atlantic and southeastern regions of the United States 1419 (e.g., Virginia Beach, Virginia and Atlanta, Georgia). Data source: 1981-2010 climate normals, 1420 World Meteorological Organization (https://climatedata-catalogue.wmo.int; accessed 24 Sep 1421 2021).
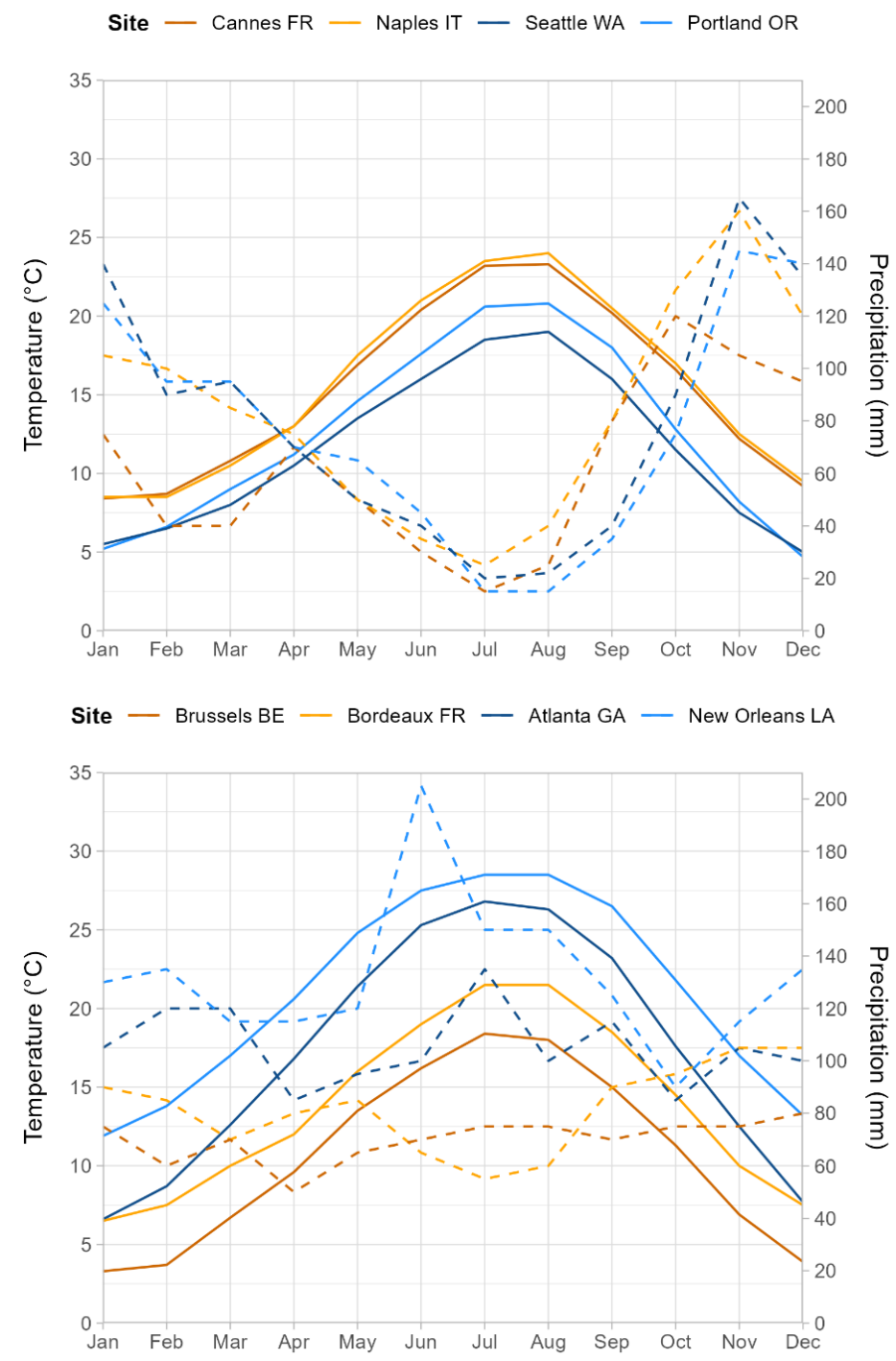